NBER WORKING PAPER SERIES

\title{
DO TEMPORARY HELP JOBS IMPROVE LABOR MARKET OUTCOMES FOR LOW-SKILLED WORKERS? EVIDENCE FROM 'WORK FIRST'
}

\author{
David H. Autor \\ Susan Houseman \\ Working Paper 11743 \\ http://www.nber.org/papers/w11743
NATIONAL BUREAU OF ECONOMIC RESEARCH
1050 Massachusetts Avenue
Cambridge, MA 02138
November 2005

This research was supported by the Russell Sage Foundation and the Rockefeller Foundation. We are particularly grateful to Joshua Angrist, Orley Ashenfelter, Tim Bartik, Mary Corcoran, John Earle, Randy Eberts, Jon Gruber, Brian Jacob, Lawrence Katz, Alan Krueger, Andrea Ichino, Pedro Martins, Justin McCrary, Albert Saiz and seminar participants at MIT, the NBER Summer Institute, the Upjohn Institute, the University of Michigan, Michigan State University, the Center for Economic Policy Research, the Bank of Portugal, and the Schumpeter Institute of Humboldt University for valuable suggestions. We are indebted to Lillian Vesic-Petrovic for superb research assistance and to Lauren Fahey, Erica Pavao, and Anne Schwartz for expert assistance with data. Autor acknowledges generous support from the Sloan Foundation, the National Science Foundation (CAREER award SES-0239538), and the MIT Ferry Family Fund. The views expressed herein are those of the author(s) and do not necessarily reflect the views of the National Bureau of Economic Research.

(C) 2005 by David H. Autor and Susan Houseman. All rights reserved. Short sections of text, not to exceed two paragraphs, may be quoted without explicit permission provided that full credit, including (C) notice, is given to the source. 
Do Temporary Help Jobs Improve Labor Market Outcomes for Low-Skilled Workers? Evidence from 'Work First'

David H. Autor and Susan Houseman

NBER Working Paper No. 11743

November 2005, Revised January 2008

JEL No. I38,J20,J30,J40

\begin{abstract}
A disproportionate share of low-skilled U.S. workers is employed by temporary-help firms. These firms offer rapid entry into paid employment, but temporary-help jobs are typically brief, and it is unknown whether they foster longer-term employment. We exploit a unique aspect of the city of Detroit's welfare-to-work program, in which one in five jobs taken is obtained with a temporary-help firm, to identify the effects of temporary-help jobs on the subsequent labor market advancement of low-skilled workers. Welfare participants are assigned on a rotating basis to one of numerous program providers that have substantially different placement rates into temporary-help and regular ('direct-hire') jobs but offer otherwise standardized services. This gives rise to variation in job-taking rates that is functionally equivalent to random assignment. Using provider assignments as instrumental variables, we find that temporary-help job placements yield significant short-term earnings gains, but these gains are offset by lower earnings and less frequent employment over the next one to two years. Job placements with direct-hire employers, by contrast, substantially raise earnings over one, two, and three years following placement. The primary observable difference between these types of job placements is their effect on subsequent employment stability. Direct-hire placements roughly double the probability of ongoing employment in each of the first eight quarters following program assignment, while temporary help placements only positively affect the probability of ongoing employment for two quarters and do not facilitate transitions to direct-hire jobs. These results qualify the interpretation of a large experimental literature documenting the benefits of job placement services for labor market outcomes of low-skilled workers. We find that the benefits of job placements derive entirely from direct-hire jobs; placing low-skilled workers in temporary-help jobs is no more effective than providing no job placements at all.
\end{abstract}

David H. Autor

Department of Economics

MIT, E52-371

50 Memorial Drive

Cambridge, MA 02142-1347

and NBER

dautor@mit.edu

Susan Houseman

Upjohn Institute

Kalamazoo, MI

houseman@upjohninstitute.org 
A disproportionate share of low-skilled and minority U.S. workers is employed by temporary-help firms. ${ }^{1}$ Within the low-skill population, employment in temporary help is especially prevalent among participants in public employment and training programs. Although the temporary-help industry accounts for less than 3 percent of average daily employment in the United States, state administrative data show that 15 to 40 percent of former welfare recipients who obtained employment in the years following the 1996 U.S. welfare reform took jobs in the temporary-help sector. ${ }^{2}$ Comparing the industry distribution of employment of participants in Missouri welfare, job training, and labor exchange programs before and immediately following program participation, Heinrich, Mueser, and Troske (2007) find that participation in government programs is associated with a 50 to 100 percent increase in employment in temporary-help firms and that no other industry displays such a spike in employment.

The concentration of low-skilled workers in the temporary-help sector and the high employment rates of participants in government employment programs in temporary-help jobs have catalyzed a debate as to whether temporary-help jobs facilitate or hinder labor market advancement. Lack of employment stability is the principal obstacle to economic self-sufficiency among the low-skilled population, and thus a main goal of welfare-to-work and other employment programs targeting lowskilled workers is to help participants find stable employment (Bloom et al. 2005). Temporary-help jobs are typically less stable than regular ('direct-hire') jobs. ${ }^{3}$ Nevertheless, it is plausible that, by providing an opportunity to develop contacts with potential employers and acquire other types of human capital, temporary-help jobs allow workers to transition to more stable employment than they otherwise would have attained. Moreover, because temporary-help firms face relatively low screening and termination costs, numerous researchers have posited that they may hire individuals who otherwise would have difficulty finding any employment, and that this may lead directly or indirectly to employment in direct-hire positions (Abraham 1988; Katz and Krueger 1999; Autor 2001 and 2003; Houseman 2001; Autor and Houseman 2002b; Houseman, Kalleberg, and Erickcek 2003; Kalleberg, Reynolds, and Marsden 2003).

\footnotetext{
${ }^{1}$ In 2005, high school dropouts comprised 17 percent of workers in temporary-help employment and only 9 percent of workers in direct-hire employment. The comparable percentages for African Americans were 23 percent and 11 percent. In contrast, those with college degrees made up only 21 percent of temporary-help workers and about 33 percent of workers in direct-hire employment (U.S. Department of Labor, Bureau of Labor Statistics 2005).

${ }^{2}$ See Autor and Houseman (2002b) on Georgia and Washington state; Cancian et al. (1999) on Wisconsin; Heinrich, Mueser, and Troske (2005) on North Carolina and Missouri; and Pawasarat (1997) on Wisconsin. Heinrich, Mueser and Troske (2007) estimate that participation in welfare-to-work, job training, and employment services in Missouri increases the likelihood that workers take temporary-help positions by 50 to 100 percent.

${ }^{3}$ In a six-city study of welfare recipients that controls for individual fixed effects, King and Mueser (2005) find that, among all industries, the temporary help sector provides the shortest expected employment durations and the lowest quarterly earnings.
} 
Offering a contrasting hypothesis, a set of scholars and practitioners have argued that the unstable and primarily low-skilled jobs offered by temporary-help firms provide little opportunity for workers to invest in human capital or engage in productive job search (Parker 1994; Pawasarat 1997; Jorgenson and Riemer 2000; Benner, Leete and Pastor, 2007). This hypothesis, however, only implies that temporary-help jobs inhibit labor market advancement if these jobs displace more productive employment activities. Thus, a central question for evaluation is whether temporary-help positions crowd out other job search and human capital acquisition activities.

Distinguishing among these competing hypotheses poses an empirical challenge. It is inherently difficult to differentiate the effects of holding given job types from the skills and motivations that cause workers to hold these jobs initially. This issue is not amenable to study with a traditional randomized experimental design since it is infeasible to coerce workers to obtain different types of jobs. The inference problem is particularly acute in the setting we study because low-skill workers in general - and welfare clients in particular - cycle regularly through states of employment and nonemployment. For example, the modal worker in our sample of low-skilled workers from Detroit works only two of every four quarters, and workers found in either temporary-help or direct-hire jobs at a point in time are clearly positively self-selected relative to welfare recipients who are not working. Absent a source of variation that causally affects the probability that workers obtain temporary-help or direct-hire employment but is otherwise uncorrelated with workers' skills and motivations, statistical comparisons of workers by job type appear likely to yield biased estimates of the causal effects of job-holding.

This study exploits a unique aspect of the city of Detroit's welfare-to-work program (Work First) to identify the causal effects of temporary-help and direct-hire jobs on the subsequent labor market advancement of low-skilled workers. Welfare participants in Detroit are assigned on a rotating basis to one of numerous not-for-profit program providers - termed contractors - that have substantially different placement rates into temporary-help and direct-hire jobs but offer otherwise standardized services. As we demonstrate below, this rotational assignment is functionally equivalent to random assignment of participants to Work First contractors, leading to a setting where contractor assignments are uncorrelated with participant characteristics but are correlated with the probability that participants are placed into a direct-hire job, a temporary-help job, or no job during their Work First spells. These program features enable us to use contractor assignments as instrumental variables for job-taking. This identification strategy is analogous to that in Kling (2005) and Doyle (2007), both 
of whom use administrative assignment mechanisms as instrumental variables to identify plausibly exogenous variation in 'treatments' that are otherwise difficult to randomly assign-prison sentences in the case of Kling and foster care assignment in the case of Doyle. Distinct from these studies, we analyze the causal effects of two endogenous variables simultaneously: temporary-help and direct-hire employment. Our econometric framework lays out the conditions necessary for valid causal inference in this multiple endogenous variable setting.

Our analysis draws on administrative records from the Detroit Work First program linked with Unemployment Insurance (UI) wage records for the entire State of Michigan for over 37,000 Work First spells commencing between 1999 and 2003. ${ }^{4}$ The administrative data provide person-level demographic information on Work First participants and the jobs they obtain during their Work First spells. The UI wage records track participants' quarterly earnings in each job held for two years before entering the program and for two to three years following program participation. Consistent with welfare populations studied in Georgia, Washington, North Carolina, Missouri, and Wisconsin, the incidence of temporary-help employment is in Detroit is high; one in five jobs obtained during Work First contractor assignments is obtained with a temporary-help firm. This provides ample variation to simultaneously analyze the causal effects of direct-hire and temporary-help jobs on subsequent labor market outcomes.

The analysis yields two main results. Direct-hire placements induced by contractor assignments raise Work First participants' payroll earnings by two to three thousand dollars per year - approximately a 40 percent increase over baseline for this low-skill population - and increase time employed by one to two quarters in each of the subsequent three years calendar years. These effects are highly statistically significant and are economically large. Temporary-help placements, by contrast, only significantly raise employment and earnings in the first quarter following contractor assignment. These benefits wash out within a year, and the estimated effects of temporary-help placements on employment and earnings become slightly negative thereafter. The precision of these estimates rules out even moderately positive effects of temporary-help job placements. The 95 percent confidence interval of the estimates excludes cumulative earnings gains over two calendar years larger than $\$ 800$ and employment gains greater than one-half a calendar quarter.

Complementary analyses provide insights into why direct-hire placements improve long-term labor market outcomes while temporary-help placements fail to do so. The primary observable difference in

\footnotetext{
${ }^{4}$ We are particularly grateful to Cylenthia Miller and Deborah Watson for providing access to these data.
} 
the effects of these job types is their effect on job stability. Placements into direct-hire jobs increase the subsequent probability of having one employer per quarter, raise tenure and earnings in the longestheld job, and approximately double the probability of ongoing employment in the subsequent eight quarters. Placements into temporary-help jobs do not foster transitions to direct-hire jobs and, in the first year following contractor assignment, only increase earnings in the temporary help sector while crowding out earnings in direct-hire jobs by approximately offsetting amounts. Consistent with this finding, temporary-help placements increase the probability of having multiple employers or no employer in a calendar quarter, reduce tenure and earnings in the longest-held job, and have no effect on the probability of on-going employment after two quarters. In net, relative to no job placement, temporary-help placements have no beneficial or detrimental effect on earnings, employment, or labor market advancement of low-skilled workers over any significant time-span.

We emphasize that our results pertain to the marginal temporary-help job placements induced by the randomization of Work First clients across contractors, and therefore do not preclude the possibility that infra-marginal temporary-help placements generate significant benefits. Using methods proposed by Abadie (2002), we estimate the characteristics of marginal workers - those whose job placements are causally affected by program assignments - and compare them to the full set of job takers in the Work First population. Logically, marginal workers have somewhat weaker prior earnings histories than do average job takers - though the differences are surprisingly small and are insignificant at conventional levels. We further estimate that marginal direct-hire and marginal temporary-help workers have comparable prior earnings and employment histories, implying that the causal effects estimates for these job types are identified by comparable treatment populations. In conjunction with our main results, this suggests that had marginal workers been placed in direct-hire rather than temporary-help jobs, they would likely have fared better.

We provide a variety of tests of the robustness and plausibility of these results. We demonstrate that our findings are robust to alternative specifications of the instrumental variables and confirm that our results do not suffer from weak instruments biases. We also carefully evaluate a potential threat to validity of the analytic framework. The use of contractor assignments as instrumental variables for job placement types requires that either contractors only affect participant outcomes through their influence on the types of jobs that they take or, alternatively, that any other effects that contractors may have on participant outcomes is orthogonal to the effect operating through job placement. We argue that, by design, there is little scope for contractors to substantially affect participant outcomes 
through any modality other than job placements. Consistent with this contention, we demonstrate that the effect of contractor assignments on participant outcomes is fully captured by contractors' placement rates into temporary-help and direct-hire jobs.

Our findings are pertinent to the economics literature on active labor market programs designed to improve employment and earnings among low-skilled workers. Large-scale random assignment experiments conducted with welfare-to-work and adult disadvantaged populations in the 1990s found that, compared to more costly intervention strategies, job placement services were as or more effective at improving subsequent labor market outcomes (see Bloom et al. and Bloom and Michalopoulos 2001 for summaries). This experimental evidence provided a research basis for the "Work First" approach to welfare-to-work programs used in Michigan and most other states. Consistent with this experimental literature, we estimate that job placements significantly improve affected workers' longterm employment and earnings outcome. However, we also find that the benefits of job placement services derive entirely from placements into direct-hire jobs, thus placing an important qualification on the conventional wisdom that placement into any job is better than no job.

Most closely related to the present analysis are a handful of recent U.S. studies that estimate the effects of temporary-help employment on subsequent labor market outcomes of low-skill and low-income populations, and a parallel European literature that evaluates whether temporary-help employment, as well as fixed-term contracts, provide a stepping stone into stable employment. ${ }^{5}$ To account for the likely non-random selection of workers with different earnings capacities and motivations to work into different job types, these studies use a variety of statistical control approaches including include regression control, matching, fixed-effects, selection-adjustment, and structural estimation techniques. With the exception of Benner, Leete and Pastor (2007), these U.S. and European studies uniformly conclude that temporary-help jobs benefit workers, either by facilitating longer-term labor market attachment or, at a minimum, by substituting for spells of unemployment. ${ }^{6}$

Our study differs from this work in two key respects. First, our research design exploits a source of plausibly exogenous variation in temporary-help and direct-hire job-taking, stemming from adminis-

\footnotetext{
${ }^{5}$ U.S. studies include Ferber and Waldfogel (1998), Lane et al. (2003), Corcoran and Chen (2004), Andersson, Holzer and Lane (2005, 2007), Heinrich, Mueser, and Troske (2005, 2007), and Benner, Leete and Pastor (2007). Studies on temporary help and fixed-term contract employment in Europe include Booth, Francesconi, and Frank (2002), GarcíaPérez and Muñoz-Bullón (2002), Andersson and Wadensjö (2004), Zijl, van den Berg, and Hemya (2004), Ichino, Mealli and Nannicini (2005, forthcoming), Gerfin, Lechner and Steiger (2005), Amuedo-Dorantes, Malo, and Muñoz-Bullón (2005), Böheim and Cardoso (2007), Kvasnicka (2007).

${ }^{6}$ Given the diversity of labor market institutions in European economies, there is no presumption that the crosscountry findings should be comparable. This makes it all the more striking that studies in this literature have developed such consistent results.
} 
trative assignments. Second, our analysis finds that temporary-help jobs do not improve labor-market outcomes of low-skilled workers. To assess why our results differ from the literature, we estimate detailed OLS models, akin to those found in earlier studies, of the relationship between temporaryhelp employment and subsequent labor market outcomes. These estimates are closely comparable to those in the literature, suggesting that the discrepancy between our findings and prior work is due to substantive differences in methodology rather than discrepancies in sample frame. We suggest two potential reconciliations for these disparate findings. There may be substantial differences between the marginal treatment effects of temporary-help placements recovered by our instrumental variables estimates and the average treatment effects recovered by other estimators. Alternatively, the statistical techniques used in the literature may be unable to fully differentiate the causal effects of holding given job types from the unmeasured skills and motivations that cause self-selection into these jobs.

\section{Context: Work First Contractor Assignments in Detroit}

Our study exploits the unique structure of Detroit's welfare-to-work program to identify the long-term consequences of temporary-help and direct-hire employment on labor market outcomes of low-skilled workers. Most recipients of TANF benefits ('Temporary Assistance for Needy Families') must fulfill mandatory minimum work requirements. TANF applicants in Detroit who do not already meet these work requirements are assigned to Work First programs, which serve to place them in employment. For administrative purposes, Detroit's welfare and Work First programs are divided into fourteen geographic districts. TANF participants are assigned to districts according to zip code of residence. The City of Detroit administers the Work First program, but the provision of services is contracted out to non-profit or public organizations. One to three Work First contractors service each district, and when multiple contractors provide Work First services within a district, the City's Work First office rotates the assignment of participants to contractors on a weekly basis. The contractor to which a participant is assigned thus depends on the date that he or she applies for TANF.

Figure 1 provides a schematic diagram of Detroit's Work First program and the rotational assignment of participants to contractors. Upon entry, participants, who vary in terms of their personal characteristics and work histories, are assigned to a contractor operating in their district. ${ }^{7}$ All contractors operating in Detroit offer a fairly standardized one-week orientation. Following orientation, participants must search intensively for a job. Few resources are spent on anything but job devel-

\footnotetext{
${ }^{7}$ Participants reentering the system for additional Work First spells follow the same assignment procedure and thus may be reassigned to another contractor.
} 
opment, and the general or life skills training provided in the first week of the Work First program is very similar across contractors. Support services intended to aid job retention, such as childcare and transportation, are equally available to participants in all contractors and are provided outside the program (Autor and Houseman 2005). Contractors play an integral role in helping to place participants into jobs, but systematically vary in their propensities to place participants into direct-hire, temporary-help, or, indeed any job at all.

It is logical to ask why contractors' placement practices vary. The most plausible answer is that contractors are uncertain about which types of job placements are most effective and hence pursue different policies. Contractors do not have access to UI wage records data (used in this study to assess participants' labor market outcomes), and they collect follow-up data only for a short time period and only for individuals placed in jobs. Hence, they cannot rigorously assess whether job placements improve participant outcomes or whether specific job placement types matter. During inperson and phone interviews conducted for this study, contractors expressed considerable uncertainty, and differing opinions, about the long-term consequences of temporary job placements (Autor and Houseman 2005).

\section{ECONOMETRIC FrameWORK}

This section outlines a simple econometric framework that highlights the conditions under which the use of rotational assignment of participants to contractors can generate valid causal effects estimates for the treatments of interest - temporary-help and direct-hire job placements.

Let the set of potential outcomes of welfare participants equal $Y_{(i)} \in\left\{Y_{(i) 0}, Y_{(i) 1}, Y_{(i) 2}\right\}$, corresponding to subsequent (i.e., post Work First) outcomes for participants receiving no job placement, a temporary-help agency job placement, or a direct-hire job placement, respectively, during their Work First spell. We define the causal effect of a temporary-help agency placement as $Y_{1}-Y_{0}$ and the causal effect of a direct-hire placement as $Y_{2}-Y_{0} \cdot{ }^{8}$ For each participant, we only observe one outcome, $Y_{i}=Y_{(i) 0} D_{(i) 0}+Y_{(i) 1} D_{(i) 1}+Y_{(i) 2} D_{(i) 2)}$, where $D_{(i) 0}, D_{(i) 1}, D_{(i) 2}$ are binary variables indicating whether a participant received no placement, a temporary-help placement, or a direct-hire job placement, respectively, during her Work First spell.

Let $Z_{0}, Z_{1}, Z_{2}$ be a set of binary instruments, representing contractor assignments. These $Z^{\prime}$ s are independent of potential outcomes $Y_{0}, Y_{1}, Y_{2}$ but that are correlated with $D_{0}, D_{1}, D_{2}$ in the population.

\footnotetext{
${ }^{8}$ The choice of $Y_{0}$ as the comparison state is innocuous since the three potential outcomes yield exactly two unique contrasts.
} 
We define a set of indicator variables that reflects the potential job placements that participants would obtain if assigned to each contractor. Let $D_{d z}=D_{d} \mid Z_{z}=1$. Thus, for example, a participant for whom $D_{(i) 20}=1$ and $D_{(i) 11}=1$ would obtain a direct-hire job placement if assigned to contractor 0 and a temporary-help placement if assigned to contractor 1 . Note that one potential placement outcome occurs for each participant at each value of the instrument. So, $\sum_{d=1}^{3} D_{d z}=1$ for $Z \in\{1,2,3\}$. We make the following identifying assumption:

Assumption 1 Independence of the instrument: The random vector $\left(Y_{(i) 0}, Y_{(i) 1}, Y_{(i) 2}, D_{(i) 0 z}, D_{(i) 1 z}, D_{(i) 2 z}\right)$ is independent of the instruments $Z_{0}, Z_{1}$ and $Z_{2}$.

We anticipate that this assumption will be satisfied due to the rotational assignment of participants to contractors. In section 3 , we test and affirm one observable implication of this assumption, which is that pre-determined participant covariates, such as age, race, gender and prior earnings and quarters of employment in direct-hire and temporary-help employment, are balanced among participants assigned to contractors within each district.

We can characterize the expected outcomes of participants randomly assigned to each contractor as:

$$
\begin{aligned}
& E[Y \mid Z=0]=E\left[Y_{0}\left(1-D_{10}-D_{20}\right)\right]+E\left[Y_{1} D_{10}\right]+E\left[Y_{2} D_{20}\right], \\
& E\left[Y_{0}\right]+E\left[\left(Y_{1}-Y_{0}\right) D_{10}\right]+E\left[\left(Y_{2}-Y_{0}\right) D_{20}\right], \\
& E[Y \mid Z=1]=E\left[Y_{0}\right]+E\left[\left(Y_{1}-Y_{0}\right) D_{11}\right]+E\left[\left(Y_{2}-Y_{0}\right) D_{21}\right], \\
& E[Y \mid Z=2]=E\left[Y_{0}\right]+E\left[\left(Y_{1}-Y_{0}\right) D_{12}\right]+E\left[\left(Y_{2}-Y_{0}\right) D_{22}\right] .
\end{aligned}
$$

Contrasting the outcomes of participants randomly assigned to contractors 1 and 2 relative to contractor 0 yields:

$$
\begin{aligned}
& E[Y \mid Z=1]-E[Y \mid Z=0]=E\left[\left(Y_{1}-Y_{0}\right)\left(D_{11}-D_{10}\right)\right]+E\left[\left(Y_{2}-Y_{0}\right)\left(D_{21}-D_{20}\right)\right], \\
& E[Y \mid Z=2]-E[Y \mid Z=0]=E\left[\left(Y_{1}-Y_{0}\right)\left(D_{12}-D_{10}\right)\right]+E\left[\left(Y_{2}-Y_{0}\right)\left(D_{22}-D_{20}\right)\right] .
\end{aligned}
$$

Equations (1) and (2) highlight a central feature of the econometric identification that arises from our institutional setting. The contrast among outcomes of participants randomly assigned to any two contractors combines two sources of variation: a contrast of the outcomes of participants induced by program assignment to obtain a temporary-help placement instead of no job placement or vice versa (e.g., $D_{(i) 11}>D_{(i) 10}$ or $D_{(i) 11}<D_{(i) 10}$ in equation $(1)$, and $D_{(i) 12}>D_{(i) 10}$ or $D_{(i) 12}<D_{(i) 10}$ in equation (2)) and a contrast of the outcomes of participants induced by program assignment to obtain a direct-hire placement instead of no job placement or vice versa (e.g., $D_{(i) 21}>D_{(i) 20}$ or 
$D_{(i) 21}<D_{(i) 20}$ in equation $(1)$, and $D_{(i) 22}>D_{(i) 20}$ or $D_{(i) 22}<D_{(i) 20}$ in equation $\left.(2)\right) .{ }^{9}$ We denote these four contrasts - two each arising from the contrast between a pair of contractors - as:

$$
\begin{aligned}
& \delta_{11}=E\left[Y_{1}-Y_{0} \mid D_{11} \neq D_{10}\right], \delta_{21}=E\left[Y_{2}-Y_{0} \mid D_{21} \neq D_{20}\right] \text {, } \\
& \delta_{12}=E\left[Y_{1}-Y_{0} \mid D_{12} \neq D_{10}\right], \delta_{22}=E\left[Y_{2}-Y_{0} \mid D_{22} \neq D_{20}\right] \text {. }
\end{aligned}
$$

Since we have two equations with four unknowns, it is not possible to obtain causal effects estimates of temporary-help and direct-hire placements without further identifying assumptions. We now consider two alternative sets of assumptions that permit identification. ${ }^{10}$

\subsection{Case 1: Locally constant treatment effects}

Consider the following 'locally constant' treatment effects assumptions:

Assumption 2 Locally constant effect of temporary-help employment: $Y_{(i) 1}-Y_{(i) 0}$ is constant for all participants whose placement outcome is changed from no placement to temporary-help or vice versa by random assignment to either program 1 or program 2.

Assumption 3 Locally constant effect of direct-hire employment: $Y_{(i) 2}-Y_{(i) 0}$ is constant for all participants whose placement outcome is changed from no placement to direct-hire or vice versa by random assignment to either program 1 or program 2.

Assumptions (2) and (3) imply that $\delta_{11}=\delta_{12}$ and $\delta_{21}=\delta_{22}$ : the causal effect of a temporary-help placement is constant for the subpopulation whose temporary-help placement outcome is causally affected by assignment to any program, and similarly for direct-hire placements.

Under these assumptions, we can obtain causal effects estimates of the treatments of interests by combining equations (1) and (2) to solve:

$$
\begin{aligned}
{\left[\begin{array}{c}
\hat{\delta}_{1} \\
\hat{\delta}_{2}
\end{array}\right]=} & {\left[\begin{array}{ll}
E\left[D_{1} \mid Y=1\right]-E\left[D_{1} \mid Y=0\right] & E\left[D_{2} \mid Y=1\right]-E\left[D_{2} \mid Y=0\right] \\
E\left[D_{1} \mid Y=2\right]-E\left[D_{1} \mid Y=0\right] & E\left[D_{2} \mid Y=2\right]-E\left[D_{2} \mid Y=0\right]
\end{array}\right]^{-1} } \\
& \times\left[\begin{array}{c}
E[Y \mid Z=1]-E[Y \mid Z=0] \\
E[Y \mid Z=2]-E[Y \mid Z=0]
\end{array}\right]
\end{aligned}
$$

where $\delta_{1}=\delta_{11}$ and $\delta_{2}=\delta_{22}$. Thus, $\delta_{1}$ and $\delta_{2}$ can be estimated using standard 2SLS techniques.

\footnotetext{
${ }^{9}$ Note that the contrast between those induced to take direct-hire instead of temporary-help placements (or vice versa) is implicit in equation (1). Consider, for example, a participant for whom $D_{20}=1$ and $D_{11}=1$. This participant would take a direct-hire position if assigned to contractor 0 and a temporary-help position if assigned to contractor 1 . For this participant, equation (1) reduces to: $E[Y \mid Z=1]-E[Y \mid Z=0]=\left(Y_{1}-Y_{0}\right)-\left(Y_{2}-Y_{0}\right)=Y_{1}-Y_{2}$.

${ }^{10}$ Although we have two causal effects estimates for each job type, these estimates do not necessarily identify the same parameter since the set of participants whose job placements are causally affected by program assignments may differ between programs 1 and 2 .
} 
We refer to this case as a 'locally constant treatment effects' because it requires only that treatment effects are constant for the subpopulation of participants whose employment outcomes are causally effected by random assignments. This is less restrictive than the conventional assumption that causal effects are constant in the full treatment population.

\subsection{Case 2: Local average treatment effects With indePendent instruments}

An alternative set of assumptions, based on the Local Average Treatment Effects (LATE) framework of Imbens and Angrist (1996), also is potentially applicable in our setting.

Discarding assumptions (2) and (3), consider the following alternative assumptions:

Assumption 4 No effect of $Z_{1}$ on $D_{2}$ (direct-hire job placements): $D_{21}=D_{20}$.

Assumption 5 No effect of $Z_{2}$ on $D_{1}$ (temporary-help job placements): $D_{12}=D_{10}$.

Assumption 6 Monotonicity of response to each instrument: $\operatorname{Pr}\left(D_{11} \geq D_{10}\right)=1$ and $\operatorname{Pr}\left(D_{22} \geq D_{20}\right)=$ 1.

These assumptions imply that we can estimate treatment effects for temporary-help placements by contrasting outcomes between contractors 1 and 0 and estimate treatment effects for direct-hire placements from the contrast between contractors 2 and 0. Applying monotonicity, we can rewrite equations (1) and (2) as:

$$
\begin{aligned}
& E[Y \mid Z=1]-E[Y \mid Z=0]=E\left[Y_{1}-Y_{0} \mid D_{11}>D_{10}\right] \cdot \operatorname{Pr}\left(D_{11}>D_{10}\right) \\
& +E\left[Y_{2}-Y_{0} \mid D_{21}>D_{20}\right] \cdot \operatorname{Pr}\left(D_{21}>D_{20}\right)
\end{aligned}
$$

and

$$
\begin{aligned}
& E[Y \mid Z=2]-E[Y \mid Z=0]=E\left[Y_{1}-Y_{0} \mid D_{12}>D_{10}\right] \cdot \operatorname{Pr}\left(D_{12}>D_{10}\right) \\
& +E\left[Y_{2}-Y_{0} \mid D_{22}>D_{20}\right] \cdot \operatorname{Pr}\left(D_{22}>D_{20}\right) .
\end{aligned}
$$

Using assumptions (4) and (5), these equations simplify further to:

$$
E[Y \mid Z=1]-E[Y \mid Z=0]=E\left[Y_{1}-Y_{0} \mid D_{11}>D_{10}\right] \cdot \operatorname{Pr}\left(D_{11}>D_{10}\right)
$$

and

$$
E[Y \mid Z=2]-E[Y \mid Z=0]=E\left[Y_{2}-Y_{0} \mid D_{22}>D_{20}\right] \cdot \operatorname{Pr}\left(D_{22}>D_{20}\right) .
$$

Thus, causal effects estimates of temporary-help and direct-hire placements can be obtained by estimating separate Instrumental Variables (2SLS) models of equations (3) and (4) using only instruments 
$Z_{1}, Z_{0}$ for equation (3) and $Z_{2}, Z_{0}$ for equation (4). In particular,

$$
\begin{aligned}
& \hat{\delta}_{1}=(E[Y \mid Z=1]-E[Y \mid Z=0]) /\left(E\left[D_{1} \mid Z=1\right]-E\left[D_{0}=1 \mid Z=0\right]\right), \\
& \hat{\delta}_{2}=(E[Y \mid Z=2]-E[Y \mid Z=0]) /\left(E\left[D_{2} \mid Z=2\right]-E\left[D_{0}=1 \mid Z=0\right]\right) .
\end{aligned}
$$

Since these are effectively independent LATE estimates obtained using the population, control variables and outcome measures, they can also be estimated simultaneously as a single equation with two-endogenous variables and two instruments.

In actuality, the quasi-experiment that we exploit randomizes participants among a total of 31 contractors, with 2 or 3 contractors serving each of 12 randomization districts. If assumptions (4) and (5) are applicable in this broader setting, they require that the contrast among any two contractors within a randomization district is due to causal variation in either direct-hire or temporary-help placement rates but not both. We take a statistical approach to assessing the applicability of the identifying assumptions. Assumptions (4) and (5) imply that the instruments for temporary-help and direct-hire placements are independent. That is, the $Z_{2}$ instrument vector induces no variation in temporaryhelp placements and the $Z_{1}$ instrument vector induces no variation in direct-hire placements. If this independence condition holds, estimates of $\delta_{1}$ and $\delta_{2}$ using all $Z$ 's as instruments should be statistically indistinguishable whether estimated simultaneously, as a system of two equations, or estimated individually, one endogenous variable at a time. In section 6 we directly test this implication and accept the null that estimates of $\delta_{1}$ and $\delta_{2}$ are invariant to whether these parameters are estimated individually or simultaneously. We interpret our main results as reflecting the Local Average Treatment Effect of temporary-help and direct-hire job placements on complier subpopulations in the Work First population, though the 'locally constant' interpretation is also possible.

The LATE framework also highlights a subtlety for the interpretation of our findings. Since the complier populations for the temporary-help and direct-hire treatments are potentially distinct, our analysis does not directly estimate the temporary-help treatment effect for the direct-hire complier population or the direct-hire treatment effect for the temporary-help complier population. ${ }^{11}$ In Section 7, we use methods proposed by Abadie (2002) to infer the characteristics of the subpopulations whose placement into temporary-help and direct-hire jobs was impacted by contractor assignment and find that these subpopulations are largely comparable along dimensions of prior earnings and employment. This in turn suggests that the treatment effects of direct-hire and temporary-help employment may also be comparable for these subpopulations.

\footnotetext{
${ }^{11}$ That is, our experiment provides estimates of $E\left[Y_{1}-Y_{0} \mid D_{11}>D_{10}\right]$ and $E\left[Y_{2}-Y_{0} \mid D_{22}>D_{20}\right]$ but does not provide estimates of $E\left[Y_{1}-Y_{0} \mid D_{22}>D_{20}\right]$ and $E\left[Y_{2}-Y_{0} \mid D_{11}>D_{10}\right]$.
} 


\section{The Research Design}

Our research data comprise Work First administrative records data linked to quarterly earnings from the State of Michigan's unemployment insurance wage records data base. We use administrative data on all Work First spells initiated from the fourth quarter of 1999 through the first quarter of 2003 in Detroit. The administrative data contain detailed information on jobs obtained by participants while in the Work First program. To classify jobs into direct-hire and temporary-help, we use the names of employers at which participants obtained jobs in conjunction with carefully compiled lists of temporary-help agencies in the metropolitan area. ${ }^{12}$ The UI data include total earnings by employer for each calendar quarter. The data also identify the industry category of each employer. We use these data to construct pre- and post- Work First UI earnings for each participant for the eight to twelve quarters prior to and subsequent to the Work First placement. ${ }^{13}$

In the time period studied, fourteen districts in Detroit were served by two or more Work First contractors, thus making these districts potentially usable for our analysis. However, in two districts with large ethnic populations, the assignment of participants to contractors was not done on a rotating basis but rather was based on language needs. Thus, we drop these two districts from our sample. We further limit the sample to spells initiated when participants were between the ages of 16 and 64 and drop spells where reported pre- or post-assignment quarterly UI earnings exceed $\$ 15,000$ in a single calendar quarter. These restrictions reduce the sample by less than 1 percent. Finally, we drop all spells initiated in a calendar quarter in any district where one or more participating contractors received no clients during the quarter, as occasionally occurred when contractors were terminated and replaced. ${ }^{14}$

Table 1 summarizes the means of variables on demographics, work history, and earnings following program entry for all Work First participants in our primary sample as well as by placement outcome during the Work First spell: direct-hire placement, temporary-help placement, or no job placement. The sample is predominantly female (94 percent) and black (97 percent). Slightly under half (48 percent) of Work First spells resulted in job placements. Among spells resulting in jobs, 20 percent have at least one job with a temporary agency. The average earnings and total quarters of employment over

\footnotetext{
${ }^{12}$ Particularly helpful was a comprehensive list of temporary agencies operating in our metropolitan area as of 2000 , developed by David Fasenfest and Heidi Gottfried. In a small number of cases where the appropriate coding of an employer was unclear, we collected additional information on the nature of the business through an internet search or telephone contact.

${ }^{13}$ The UI wage records exclude earnings of federal and state employees and of the self-employed.

${ }^{14}$ This further reduced the final sample by 3,091 spells, or 7.4 percent. We have estimated the main models including these observations with near-identical results.
} 
the eight quarters following program entry are comparable for those obtaining temporary agency and direct-hire jobs, while earnings and quarters of employment for those who do not obtain employment during the Work First spell are 40 to 50 percent lower. ${ }^{15}$

The average characteristics of participants vary considerably according to job outcome. Those who do not find jobs while in Work First are more likely to have dropped out of high school, have worked fewer quarters before entering the program, and have lower prior earnings than those who find jobs. Among those placed in jobs, those taking temporary agency jobs actually have slightly higher average prior earnings and quarters worked than those taking direct-hire jobs. Not surprisingly, those who take temporary jobs while in the Work First program have higher prior earnings and more quarters worked in the temporary-help sector than those who take direct-hire jobs. Data used in previous studies show that blacks are much more likely than whites to work in temporary agency jobs (Autor and Houseman 2002b; Heinrich, Mueser, and Troske 2005). Even in our predominantly African-American sample, we also find this relationship.

\subsection{Testing the Research DEsign}

Our identification relies on the assumption that the rotational assignment of participants to Work First contractors effectively randomizes participants across contractors operating within each district within a particular program year. ${ }^{16}$ We test this assumption by statistically comparing the following eight characteristics of participants assigned to contractors within each district and year: sex, white race, other (non-white) race, age and its square, number of quarters worked in the eight quarters before program entry, number of quarters employed with a temporary agency in these prior eight quarters, total earnings in these prior eight quarters, and total earnings in the prior eight quarters from temporary agencies. ${ }^{17}$

In testing the comparability of participant characteristics across eight characteristics, we are likely to obtain many false rejections of the null, and this is exacerbated by the fact that participant characteristics are not fully independent. To account for these confounding factors, we estimate a Seemingly Unrelated Regression (SUR) system to test the hypothesis that the observed distribution of partic-

\footnotetext{
${ }^{15}$ Participants who do not find jobs during their Work First assignments face possible sanctions. Thus, unsuccessful participants continue to have strong return-to-work incentives after leaving Work First.

${ }^{16}$ Contractors sign annual contracts with the City of Detroit, and the set of contractors servicing a district may change from year to year.

${ }^{17}$ Because of the large number of missing values for the education measures, and because some contractors were apparently more diligent than others about recording participant education, we exclude education variables from both the randomization test and subsequent statistical analysis. Regression results that include these variables (including an "education missing" variable) are nearly identical to our main results.
} 
ipant covariates across contractors within each randomization district and year is consistent with chance. ${ }^{18}$ The SUR accounts for both the multiple comparisons problem and the correlations among demographic characteristics across participants at each contractor.

Our procedure is as follows. Let $X$ be an $8 \times N$ matrix containing the 8 baseline covariates listed above for each of the $N$ Work First spells assigned to contractors in all district and years of our sample. Let $D$ be an $N \times k$ matrix of $k$ indicator variables designating the district-year in which each spell is assigned (of which there are 41 in our sample). Let $Z$ be a $N \times(j-k)$ matrix containing a set of $j-k$ indicator variables designating the contractor and year to which each spell is assigned, with one indicator omitted for each of the $k$ district-year pairs. Finally, let $\lambda$ be a $j \times 1$ vector of parameters to be estimated and $I_{8}$ be the $8 \times 8$ identity matrix. We estimate the following SUR model:

$$
Y=I_{8} \otimes\left(\begin{array}{ll}
Z & D
\end{array}\right) \lambda+\varphi \quad Y=\operatorname{vec}\left(X^{\prime}\right) .
$$

In this expression, $Y$ is an $8 \cdot N \times 1$ vector containing the 8 rows of $X$ transposed and stacked in a column vector, and $\varphi$ is a matrix of error terms that allows for cross-equation correlations among participant characteristics at each contractor. ${ }^{19}$ The p-value of a test that the first $j-k$ elements of $\lambda$ in this regression system are jointly equal to zero provides an omnibus test for the null hypothesis that participant covariates do not differ among participants assigned to different contractors within a district and year. A high p-value corresponds to an acceptance of this null.

Appendix Table 1 provides the chi-square statistics and p-values of tests of the null hypothesis for estimates of Equation (5) for each of the 41 district-by-year cells in the sample. Consistent with the expectation that the rotational assignment of participants across contractors operating within districts is functionally equivalent to random assignment, the overall p-value of the randomization test is 0.44 , which is highly consistent with a chance distribution of covariates. Performing this statistical comparison individually for the 41 district-years in the sample, we find that 39 of 41 comparisons accept the null hypothesis at the 10 percent level or higher, and only one comparison rejects the null at conventional levels of significance. In the final row and column of the table, we also provide the p-value for the comparison test for each year, pooling across districts, and each district, pooling across years. All but one of these sixteen tests readily accepts the null at conventional levels of significance. In net, these results support the hypothesis that the rotational assignment of participants across contractors generates variation that can be treated as random.

\footnotetext{
${ }^{18}$ This method for testing randomization across multiple outcomes is proposed by Kling, Liebman and Katz (2007) in their Web Appendix available at www.nber.org/ $\mathrm{kling} / \mathrm{mto} / \mathrm{mto} \_$exp_a.pdf.

${ }^{19}$ Since the $j$ contractor dummies in $Z$ are mutually exclusive, one is dropped.
} 
Our research design also requires that random assignment to contractors significantly affects participant job placements. To confirm this, we estimated a set of SUR models akin to equation (5) where the dependent variables are participant Work First job outcomes (direct-hire, temporary-help, non-employment). Here, our expectation is that job placement outcomes should differ significantly across contractors within a district and year. Tests of this hypothesis provide strong support for the efficacy of the research design: the omnibus test for cross-contractor, within district-year differences in job placement outcomes rejects the null at below the 1 percent level for the full sample, as do 16 of 17 tests for significant differences in placement rates across all districts within a year or within a district across all years. ${ }^{20}$

\section{Main Results: The Effects of Job Placements on Earnings and Employment}

We now use the linked quarterly earnings records from the state of Michigan's unemployment insurance system to assess how Work First job placements affect participants' earnings and employment over the subsequent two to three years following the calendar quarter of random assignment to contractor. ${ }^{21}$ Our primary empirical model is:

$$
Y_{i c d t}=\alpha+\beta_{1} D_{i}+\beta_{2} T_{i}+X_{i} \beta_{3}+\gamma_{d}+\phi_{t}+\theta_{d t}+\varepsilon_{i c d t},
$$

where the dependent variable is real earnings or quarters of employment (from UI records) following the quarter of Work First assignment. Subscripts $i, d, c$, and $t$ refer, respectively to participants, placement districts, contractors, and year by quarter of participant assignment. The indicator variables $D_{i}$ and $T_{i}$ code if participant $i$ obtained either a direct-hire or temporary-help job placement during her Work First spell (with both equal to zero if no placement was obtained).

A set of pre-determined control variables are contained in $X$, including sex, race (white, black, or other), age, and measures of quarters of UI employment and real UI earnings in direct-hire and temporary-help employment in the 8 quarters prior to contractor assignment. The vectors $\gamma$ and $\phi$ contain a complete set of dummies indicating randomization districts and year by quarter of contractor

\footnotetext{
${ }^{20} \mathrm{~A}$ table of results is available from the authors. We also calculate partial R-squared values from a set of regressions of job placement type (any job placement, direct-hire job placement, temporary-help job placement) on dummy variables indicating contractor-by-year of assignment after first orthogonalizing these job placement types with respect to demographic, earnings history, and time variables; conversely, we compute partial R-squared values from regressions of job placement types on demographic, earnings history, and time variables after first orthogonalizing the dependent variable with respect to contractor assignment. We find that contractor assignment explains 85 to 130 percent as much variation in job placement type as do demographic, earnings history, and time variable combined.

${ }^{21}$ For a subset of participants, those assigned prior to 2003, we have 12 quarters of outcome data. We analyze these longer term outcomes for this subsample in Table 4.
} 
assignment, while the vector $\theta$ contains all two-way interactions between district and year. ${ }^{22}$

account for the grouping of participants within contractors, we use Huber-White robust standard errors clustered by contractor (33 clusters).

There is no mechanical linkage between job placements occurring during the Work First spell and earnings and employment outcomes observed in the UI data in post-assignment quarters. The job placement variables on the right-hand side of equation (6), $D$ and $T$, refer to jobs obtained during the Work First spell and are coded using welfare case records from the city of Detroit. The dependent variable, by contrast, is obtained from state of Michigan unemployment insurance records and measures labor market outcomes in the quarters following Work First assignment. It is therefore possible - in fact, commonplace - for a participant who obtains a job placement during Work First to have no earnings in the first quarter following program participation and, conversely, for a participant who receives no placement to have positive earnings in the post-assignment quarter.

In general, we would not expect equation (6) to recover unbiased estimates of the causal effects of job placements on participant outcomes when estimated using Ordinary Least Squares,. Only about half of Work First participants in our sample obtain employment during their Work First spell (Table 1), and this set of participants is likely to be more skilled and motivated to work than average participants. Unless these attributes are fully captured by the covariates in $X$, estimates of $\beta_{1}$ and $\beta_{2}$ are likely to be biased.

We address this bias by instrumenting $D$ and $T$ in equation (6) with contractor-by-year-ofassignment dummy variables as outlined in section 2. Our use of contractor-by-year dummy variables as instruments is almost identical to the use of contractor-by-year placement rates as instruments. ${ }^{23}$ For expositional purposes we rewrite equation (6) as,

$$
Y_{i c d t}=\alpha+\pi_{1} \bar{D}_{c t}+\pi_{2} \bar{T}_{c t}+X_{i} \beta_{3}+\gamma_{d}+\phi_{t}+\theta_{d t}+\nu_{c t}+\omega_{i c d t}
$$

where $\bar{D}_{c t}$ is the observed direct-hire placement rate of contractor $c$ in year $t$ and $\bar{T}_{c t}$ is the corresponding placement rate in temporary-help employment. The error term in this equation is partitioned into

\footnotetext{
${ }^{22}$ To conserve degrees of freedom, we do not include district by year by calendar quarter interactions. Models that include these additional dummy variables produce near-identical results and are available from the authors.

${ }^{23}$ It is almost identical because the estimates will differ to the degree that there is sample correlation between contractor dummies and participant characteristics. Due to the randomization of participants to contractors, however, this correlation is insignificant (Appendix Table 1). Accordingly, point estimates for 2SLS models are near-identical when using either placement rates or dummy variables as instruments.

An instrument analogous to equation (7) that uses means rather than fixed effects is employed by Kling (2005), who develops sentence-length propensity instruments for federal judges by regressing observed sentence outcomes on judge fixed effects and other covariates. Kling uses the estimated judge effects (a single, continuous variable) as an instrument for the sentence lengths of defendants randomly assigned to each judge.
} 
two additive components, $e_{i c d t}=\nu_{c t}+\omega_{i c d t}$. The first is a contractor-by-year random effect, $\nu$, reflecting unobserved contractor heterogeneity that affect participant outcomes but do not operate through job placement rates. The second is a participant-spell specific iid random error component.

Equation (7) underscores two key conditions that our identification strategy requires for valid inference. First, as per assumption (1) of the econometric framework, unobserved factors affecting earnings, $\omega$, must be uncorrelated with $\bar{D}_{c t}$ and $\bar{T}_{c t}$, a condition that should be satisfied by the rotational assignment design. The second condition is that any contractor-by-year random effects, if present, are mean independent of contractor placement rates, i.e., $E\left(\nu_{c t} \bar{D}_{c t}\right)=E\left(\nu_{c t} \bar{T}_{c t}\right)$. Thus, the validity of our research does not require that contractors only affect participant outcomes through job placements. It does require, however, that these non-placement effects are not systematically correlated with contractor job placement rates, because this would cause 2SLS estimates of equation (6) to misattribute the effects of unobserved contractor quality to job placement rates. As outlined in the Introduction, almost all Work First resources are devoted to job placement, and few other support services are provided to participants beyond the set of standardized services offered by the city of Detroit to all participants. Though this cannot be proven from the data, we believe it is highly unlikely that differences in contractor practices that are not directly the result of job placements can plausibly account for the very large effects we detect of contractor assignments on participant outcomes. We proceed under the assumption that the uncorrelated random effects condition is satisfied and examine corroborating evidence in Section 6.

\subsection{ORdinary Least SQUares estimates}

To facilitate comparison with prior studies of the impact of temporary-help and direct-hire job taking on labor market advancement of welfare participants and other low-earnings workers (e.g., Heinrich, Mueser and Troske 2005, 2007; Andersson, Holzer, and Lane 2005, 2007), we begin our analysis with ordinary least squares (OLS) estimates of equation (6). Table 2 presents OLS estimates for real earnings and quarters of employment for Work First participants in the first 8 quarters following their assignment to Work First contractors using all 37,163 spells in our data. For ease of interpretation, we re-center all control variables by subtracting the mean for participants who did not obtain a job during their Work First spell. Thus, by construction, the intercept in equation (6) equals the mean of the outcome variable for Work First participants not placed into jobs.

The first column of Table 2 shows that, conditional on detailed controls for race, age and prior em- 
ployment and earnings, participants who obtained any employment during their Work First spell were 36 percentage points more likely to be employed in the first quarter following contractor assignment and earned on average $\$ 804$ more than clients who did not obtain employment. As indicated by the intercepts of these equations, only 33 percent of participants who did not obtain employment during the Work First spell were employed in the post-assignment quarter, and average earnings among these participants was $\$ 494$.

Column (2) distinguishes post-Work First outcomes for those taking temporary-help from those taking direct-hire jobs during their Work First spells. Participants who obtained a temporary-help position during their Work First spell were slightly more likely to have any employment in the first post-assignment quarter and earned about 90 dollars less on average than participants who obtained a direct-hire placement. ${ }^{24}$ Though this earnings difference is statistically significant, it is not economically large.

Subsequent columns of Table 2 summarize outcomes over longer time horizons following Work First assignment. Participants who obtained a job placement during Work First earned an average of 62 percent more $(\$ 4,255)$ and worked 37 percent more quarters (1.32) over the subsequent eight quarters than did participants who did not obtain a job while in Work First. The earnings and employment gap between those obtaining temporary-help and direct-hire jobs during Work First cumulates slightly over this longer time window, but in each case remains under 10 percent over the eight quarters and is small relative to the substantial gap in employment and earnings between those who took jobs during Work First and those who did not.

These OLS estimates are consistent with other published findings, most notably with Heinrich, Mueser and Troske (2005 and 2007). They find that Missouri and North Carolina welfare recipients who obtained temporary-help jobs in 1993 and 1997 earned almost as much over the subsequent two years as those who obtained direct-hire employment - and earned much more than did non job-takers. Like Heinrich et al., our primary empirical models for earnings and employment are estimated for a relatively homogeneous and geographically concentrated population and include detailed controls for observable participant demographic characteristics and prior earnings. Similar to our estimates, Heinrich et al. report that welfare participants taking temporary-help jobs earned at least 85 percent of that of workers taking non-temporary-help jobs over the next eight calendar quarters. Though

\footnotetext{
${ }^{24}$ As shown in Table 1, temporary-help jobs typically pay hourly wages above those of direct-hire jobs. Thus, the lower post-assignment earnings - despite higher employment rates-of participants obtaining temporary-help placements likely reflects the fact that temporary-help spells are typically short, so total quarterly earnings are lower.
} 
less directly comparable, our findings also echo those of Andersson, Holzer and Lane (2005, 2007) who report that low-skilled and low-earnings workers who obtain temporary-help jobs typically fare relatively well in the labor market over the subsequent three years, despite starting with lower earnings.

These observations provide some assurance that our sample from the city of Detroit is comparable with that used in other studies of job-taking among welfare recipients and other low-skilled workers. Moreover, the rough agreement between our OLS estimates and those of Heinrich et al. for the relationship between temporary-help job-taking and subsequent earnings suggests that the differences in causal estimates that we report below from instrumental variable models are due to substantive differences in research design rather than discrepancies in sample frame.

\subsection{Instrumental Variables estimates}

Table 3 reports instrumental variables estimates of equation (6) for the impact of Work First job placements on post-assignment employment and earnings, where employment placements during the Work First spell are instrumented by contractor-by-year assignments. The column (1) estimate confirms an economically large and statistically significant effect of Work First job placements on earnings and employment in the first post-assignment quarter. Obtaining any job placement is estimated to raise the probability of employment in quarter 1 following Work First by 28 percentage points and to increase earnings by $\$ 621$. These effects are highly significant and are about 75 percent as large as the corresponding OLS estimates (Table 2).

Column (2) distinguishes between the causal effects of temporary-help and direct-hire job placements. Notably, both types of job placements significantly improve labor market outcomes in the first post-assignment quarter. Direct-hire and temporary-help placements respectively raise first-quarters earnings by $\$ 722$ and $\$ 420$ and increase the probability of any first-quarter employment by 35 and 15 percentage points, respectively. Although the temporary-help point estimates are smaller than those for direct-hire, they are statistically significantly from zero and, in the case of earnings, not statistically distinguishable from the direct-hire point estimate. Thus, Work First placements in both temporary-help and direct-hire jobs raise employment and earnings of welfare participants in the near term.

Subsequent columns of Table 3 show that the employment and earnings effects of direct-hire placements persist well beyond the first quarter. In the two years following Work First assignment, directhire placements induced by contractor assignments raise earnings and employment on average by a 
substantial and highly significant amount: the estimated earnings effect is $\$ 2,452$ in the first year and $\$ 1,720$ in the second, while the employment effect is 0.94 quarters in the first year and 0.45 quarters in the second. ${ }^{25}$

Enduring earnings and employment effects are not, however, apparent for temporary-help placements. The estimated impact of a temporary-help placement on employment and earnings in quarters two through eight is never significantly different from zero and is generally weakly negative. For example, we estimate that temporary-help placements insignificantly lower eight quarter earnings by $\$ 1,190$ and quarters of employment by 0.09. As shown in the bottom row of each column, we consistently reject the hypothesis that the impact of temporary-help and direct-hire placements on either earnings or employment is comparable.

The precision of the estimates rules out even moderately positive effects. The 95 percent confidence interval of the estimates excludes earnings gains larger than $\$ 768$ and employment gains larger than 0.37 quarters in the two years following a temporary-help placement. These best-case scenarios are less than a third as large as the mean estimates for the earnings and employment effects of direct-hire placements. Thus, the gains from temporary-help placements detected in the first quarter following Work First assignment appear transitory. In light of the fact that 20 percent of jobs obtained in Work First are temporary-help positions (Table 1), this finding is noteworthy.

Figure 2 provides further detail on these results by plotting point estimates and 95 confidence intervals for analogous 2SLS estimates of the effect of direct-hire and temporary-help job placements on employment probability and earnings for each of eight quarters following Work-First assignment. The figure shows that direct-hire placements significantly raise both earnings and the probability of employment in the first six of eight post-assignment quarters (seven quarters in the case of earnings). These impacts begin to diminish after the fifth quarter, consistent with some fade-out of benefits. By contrast, estimated impacts of temporary-help placements on employment and earnings are only significantly different from zero in the first quarter.

Analysis of outcomes of Work First participants over a three (rather than two) year horizon reinforces these conclusions. ${ }^{26}$ Estimates in Table 4 show that earnings gains from direct-hire placements

\footnotetext{
${ }^{25}$ The evidence suggesting that the benefits of job placements fade with time echoes the findings of Card and Hyslop (2005) who find, in the context of a Canadian welfare program, that initial job accessions induced by a time-limited earnings subsidy tend to peak after approximately 15 months, and in the limit, do not produce permanent earnings gains. Of course, a job placement that raises earnings and employment for two full years may still be viewed as successful from a policy perspective.

${ }^{26}$ To study outcomes over this longer interval, we limit the sample to participants who were assigned prior to 2002 and thus for whom we have three full years of outcome data.
} 
persist and remain statistically significant into the third post-assignment year. We estimate that a direct-hire placement raises earnings by approximately $\$ 8,900$ over three years, which is quite substantial relative to the mean earnings of Work First participants. Although statistically significant in each of the three post-assignment years, this impact fades in the third year. The estimated earnings gain are $\$ 3,244$ in year one, $\$ 3,593$ in year two and $\$ 2,064$ in year three.

Table 4 also confirms the result that temporary-help placements do not improve long-term employment and earnings outcomes. We cannot reject the null hypothesis that the effects of temporary-help placements on earnings and employment are zero in each of the three years following Work First assignment. These results are informative: the estimated impact of a temporary-help placement on earnings is significantly below the corresponding direct-hire effect in each year. And we can reject with 95 percent confidence that a temporary-help placement raises earnings by more than $\$ 980$ in total for the full three year post-assignment period. ${ }^{27}$

Our results provide clear evidence that direct-hire job placements induced by Work First contractor assignments substantially increase earnings and employment of Work First clients over the subsequent two to three years. In contrast to previous research, we find no evidence that comparable benefits accrue from temporary-help placements. Next we explore why temporary-help and direct-hire placements appear to have such divergent impacts on subsequent earnings and employment.

\section{The dynamics of Job Placements And EMPloyment STABILity}

Ideally, Work First job placements would result in sustained employment; participants placed into jobs during the program would remain in those jobs or would change employers with little or no interruption to employment. We assess the degree to which job placements lead to sustained employment, which we define as being continuously employed for the first $t$ quarters following Work First participation, where $t \in\{1, \ldots, 8\}$ in our data. ${ }^{28}$

To provide a baseline of comparison, panel A of Figure 3 plots the probability of continuous

\footnotetext{
${ }^{27}$ The standard errors in Tables 3 through 5 do not account for potential serial correlation in outcomes among participants with multiple spells. The 37,163 Work First spells in our data correspond to 24,903 unique participants, 67 percent of whom have one spell, 22 percent of whom have 2 spells, and 11 percent of whom have 3 or more spells. To assess the importance of this issue, we re-estimate models for total earnings and quarters worked over eight quarters using only the first Work First spell per participant observed in our data. These first-spell estimates, reported in Appendix Table 2, are largely comparable to our main estimates for earnings and employment in Tables 3 and 4 . Standard errors are approximately one-third larger, consistent with the fifty percent reduction in sample size. As in prior tables, earnings and employment impacts of direct-hire placements remain positive and highly significant while impacts of temporary-help placements are both negative and significantly below the direct-hire estimates. Notably, the point estimates for the effects of temporary-help placements are modestly statistically significant in this sub-sample.

${ }^{28}$ An employment spell requires positive earnings in sequential quarters but does not necessarily imply ongoing employment with a particular employer. Similarly, it need not be the case that the job placement obtained during the Work First spell is the same job as one observed in the UI data in the first post-assignment quarter.
} 
employment in the eight post-assignment quarters among those who were not placed into jobs during the program. The height of the first bar represents the unconditional probability of employment in post-assignment quarter one for participants not receiving a job placement during their Work First spell, and the height of subsequent bars the probability of ongoing employment in quarters two through eight for the complete set of non-placed participants (thus, the height of the second bar is by construction less than or equal to that of the first bar). The figure shows that 33 percent of participants not placed into jobs while in Work First obtain employment in the first post-assignment quarter, and 23 percent both find employment in the first quarter and maintain it into the second. By the eighth quarter, the share in ongoing employment falls to 8 percent.

Two-stage least squares estimates summarized in Panel B of Figure 3 reveal that direct-hire placements significantly raise the survivor probability of ongoing employment in all eight quarters following Work-First assignment. In the first quarter, this impact is 36 percentage points. It declines to 18 percentage points in the fourth quarter and 6 percentage points in the eighth quarter. Comparing the causal effects estimates in panel B with the baseline numbers in panel A, we see that direct-hire placements approximately double the probability of ongoing employment in each of the eight postassignment quarters. Temporary-help placements also raise the survivor probability, with an impact of 16 percentage points in the first quarter and 10 percentage points in the second (both significant at the 10 percent level). These impacts are relatively short-lived, however, and the point estimates fall to zero by the fourth quarter.

Because continuous employment may be harder to maintain for workers who repeatedly switch employers, it is informative to directly evaluate how job placements affect the long-term probability that participants work for a single primary employer. We assess this outcome first by estimating a set of 2SLS linear models for the probability that participants have either a single employer or multiple employers in each of the quarters following job placement (with no employer as the omitted category). These estimates, summarized in Figure 4, reveal that direct-hire placements significantly raise the probability that participants work for a single employer (though not necessarily the same employer) in each of the eight quarters following placement. This effect is substantial, equal to 23 percentage points in the first quarter, 20 percentage points in the fourth quarter, and 11 percentage points in the eighth quarter. Notably, direct-hire placements also raise the probability that participants work for multiple employers in each of the first two post-assignment quarters, suggesting an initial increase in job shopping or churn. But this effect becomes insignificant by the third quarter, and the point 
estimate is essentially zero thereafter. Thus, direct-hire placements lead to a near-term increase in multiple job-holding, and a near and longer-term increase in single job-holding. ${ }^{29}$

Figure 4 reveals a sharply contrasting pattern for temporary-help placements. Temporary-help placements significantly raise the probability that participants work for multiple employers in seven of the eight post-assignment quarters. At the same time, they significantly reduce the probability that participants work for a single employer in four of eight post-assignment quarters. Because the estimated reduction in the probability of single job-holding is on average larger than the estimated increase in the probability of multiple job-holding, temporary-help placements slightly reduce the probability that participants work at all (see also Figure 2).

If direct-hire employment significantly increases the probability of employment with a single employer within a particular quarter, it is likely that it also increases the probability of continued employment with a single employer across quarters. We suspect this is especially important for understanding the positive impacts of direct-hire job placements on subsequent employment and earnings because, in the two years following Work First participation, the majority of participants receive the bulk of their labor income from a continuous job spell with a single employer. For participants with positive earnings, the mean ratio of earnings in the longest-held job to total eight-quarter earnings is 80 percent with a standard deviation of 24 percent. $^{30}$

Table 5 illustrates the centrality of long job spells to the positive earnings and employment effects of direct-hire placements. For each participant, we code their longest employment spell and their longest held job observed in the eight quarters following Work First assignment. ${ }^{31}$ Table 5 shows that of the $\$ 4,173$ in additional eight-quarter earnings resulting from a direct-hire job placement, $\$ 3,885$ accrues during the longest employment spell, and $\$ 3,107$ accrues in the longest job (74 percent of the total). Similarly, of the 1.4 quarters of additional employment resulting from a direct-hire job placement, 0.9 quarters on average accrue from a single job. Thus, most of the future gains in employment and earnings resulting from direct-hire job placements come from increases in the longest job spell and the associated earnings from that spell.

\footnotetext{
${ }^{29}$ Comparing Figure 3 for multiple job-holding with Figure 2 for any employment shows that the initial 'fade out' of the effect of direct-hire placements on any employment is primarily due to a reduction in the number of participants holding two-plus jobs. By comparison, the effect of a direct-hire placement on the probability of holding a single job is much more stable.

${ }^{30}$ In the full sample of 37,163 Work First spells, mean eight-quarter earnings are $\$ 9,469$, mean earnings in the longest employment spell are $\$ 8,801$, and mean earnings in the longest job spell are $\$ 7,100$.

${ }^{31} \mathrm{An}$ employment spell is defined as a set of contiguous quarters of positive earnings and job spell is defined as a set of contiguous quarters with earnings from the same employer - though an individual may hold jobs with more than one employer in a quarter and the precise 'job' with any employer may change. Where participants have multiple jobs of the same length (in quarters), we break ties by using the highest earning spell. Note that the longest job spell is not necessarily the highest-earnings job spell, though in the vast majority of cases it is.
} 
Temporary-help placements are not found to foster long job spells. We estimate that temporaryhelp placements slightly reduce tenure and earnings in the longest job spell, and the adverse earnings effect of $\$ 1,966$ is statistically significant. Notably, earnings losses in the longest held job are larger than estimated net earnings losses of $\$ 1,190$. Thus, participants placed in temporary-help jobs partly compensate for increased instability through greater employment and earnings in other jobs.

Why do temporary-help placements fail to generate an increase in job stability? Table 6 suggests one answer: these placements do not lead to subsequent spells in direct-hire employment. This may be seen by estimating the impact of temporary-help and direct-hire placements on employment and earnings separately by employer type (that is, in temporary-help and direct-hire employment). Table 6 reveals that direct-hire job placements increase subsequent employment and earnings in direct-hire jobs significantly in both the first and second year following Work First assignment. These earnings impacts of $\$ 2,121$ and $\$ 1,711$ in years one and two are economically large - equal to essentially the entire impact of direct-hire placements on earnings in all jobs. By implication, direct-hire placements have no impact on earnings in temporary-help jobs.

Temporary-help placements significantly raise earnings in temporary-help jobs but simultaneously crowd out earnings in direct-hire jobs. Table 6 shows that in the first post-assignment year, temporaryhelp placements raise earnings and employment in temporary-help jobs by $\$ 1,042$ and 0.49 quarters respectively (both significant) and reduce earnings and employment in direct-hire jobs by $\$ 1,470$ and 0.38 quarters respectively (also significant). Hence, there is essentially one-to-one crowd-out. In the second post-assignment year, temporary-help placements have no effect on earnings or employment in either temporary-help or direct-hire jobs. Thus, despite much descriptive evidence to the contrary, we find in the Work First setting that temporary-help placements do not cause an increase in subsequent earnings and employment in direct-hire jobs. ${ }^{32}$

Taken together, these results provide insights into the sharply different causal effects of directhire and temporary-help placements on subsequent employment and earnings. Direct-hire placements appear to generate durable earnings and employment effects by fostering job stability: significantly increasing the subsequent probability of having one employer per quarter, raising tenure and earnings in the longest-held job, and approximately doubling the probability of ongoing employment in all

\footnotetext{
${ }^{32}$ In a complementary analysis, we estimate that temporary-help placements raise the number of unique temporaryhelp employers for whom a participant works by 0.60 over the first eight quarters, and similarly, direct-hire placements raise the number of unique direct-hire employers by 0.76 . Temporary-help placements have no impact on the number of direct-hire employers over eight quarters, however, and, analogously, direct-hire placements have no impact on the number of temporary help employers.
} 
eight quarters following Work-First assignment. Temporary-help placements increase the probability of having either two employers or no employer in a calendar quarter, reduce tenure and earnings in the longest-held job, and fail to raise the probability that a worker maintains ongoing employment after two quarters following placement. In net, temporary-help placements fail to foster transitions to stable employment with direct-hire employers or even to increase employment with temporary-help firms over the longer term.

\section{Testing the Identification Framework}

In this section, we probe two aspects of the identification framework. We first explore the robustness of the main results to plausible alternative specifications of the instrumental variables. We then consider the validity of the maintained assumption that contractor assignments only systematically affect participant outcomes through job placements.

\subsection{Robustness And POWer of the instruments}

As instrumental variables for job placements in Tables 3 through 7, we use contractor-by-year of assignment dummies. These instruments efficiently exploit relatively stable variation in contractors' job placement policies while allowing these policies to evolve from year to year. This over-time variation in placement rates is relevant because, as is suggested by the survey results in Autor and Houseman (2006), contractors have amended their placement polices in recent years, with a significant fraction reporting having reduced their use of temporary-help placements. ${ }^{33}$ As a robustness check on the use of contractor-by-year dummies as instruments, we report in Table 7 estimates of our main empirical model for employment and earnings using as instruments contractor assignments rather than contractor-by-year assignments. For reference, we also report in column (1) the baseline estimates. Point estimates from these contractor-only 2SLS models found in column (3) are comparable to the baseline estimates. Although standard errors are somewhat larger as expected, these estimates have sufficient power to affirm the prior conclusions: direct-hire placements significantly raise employment and earnings, and these effects are significantly larger than the corresponding effects for temporaryhelp placements, which in turn are not significantly different from zero. We can continue to exclude at the 95 percent level temporary-help placement effects on eight-quarter earnings larger than $\$ 426$.

\footnotetext{
${ }^{33}$ In addition, a time interaction between contractor and year is likely warranted because changing economic conditions affect contractors' ability to implement their preferred placement policies. For example, when temporary help positions are scarce, observed percentage point differences among contractors in temporary-help placement rates are likely to contract.
} 
Thus, even discarding the year-to-year variation in contractor placement rates, the main results are supported.

A potential concern with the use of contractor-by-year (or contractor) placements as instrumental variables, however, is that these instruments implicitly treat both past and contemporaneous variation in job placements as exogenous. Under the assumption that participants' assignments are effectively randomized by the rotational assignment structure, this contemporaneous variation should not be problematic. Indeed, for purposes of statistical efficiency, it should be exploited. It is nevertheless useful to confirm that the estimates are robust to using variation in contractor placement rates purged of contemporaneous variation. To perform this test, we construct for each participant $i$ the instrumental variables $\hat{D}_{i c t}$ and $\hat{T}_{i c t}$, which are equal to the observed job placement rates (direct-hire and temporary-help, respectively) by year of assignment for all participants at a given contractor excluding the individual participant $i$ and all other participants assigned in the same assignment cohort to the same contractor. We define cohorts by the week of participant assignment because all participants assigned to a contractor in a given week attend a week long Work First orientation at the assigned contractor. Thus, their outcomes are particularly likely to be correlated due to contemporaneous shocks. ${ }^{34}$ Estimates of the main earnings and employment models for eight quarters using as instrumental variables $\hat{D}_{i c t}$ and $\hat{T}_{i c t}$ (column 5 of Table 7 ) again prove comparable to the main estimates.

A final concern with use of contractor assignments as instruments is that they may suffer from the weak instruments problem highlighted by Bound, Jaeger and Baker (1995). According to conventional rule of thumb tests (cf. Stock, Wright and Yogo, 2002), weak instruments should not be an issue in our application; the chi-square statistics for our instrumental variables are 895, 634, and 548 for overall employment, temporary-help employment and direct-hire employment, respectively. As a further check against weak instruments, we also report in even-numbered columns of Table 7 models for the main outcomes that use a Limited Information Maximum Likelihood (LIML) estimator in place of 2SLS. Unlike 2SLS, LIML is approximately unbiased in the case of weak instruments (Angrist, Imbens and Krueger, 1999; Angrist and Krueger, 2001). For either set of dummy instrumental variablescontractor by year dummies or contractor dummies - LIML point estimates and standard errors are

\footnotetext{
${ }^{34}$ This instrument is analogous to that used by Doyle (2007), who studies the effect of placement of abused or neglected children into foster care by exploiting the rotational assignment of children to case workers who have different propensities to remove children from abusive homes. So that no contemporaneous variation is used in constructing the instrument, case worker removal propensities are calculated using observed case worker placement rates from time periods other than the one corresponding to the specific cases under study.
} 
closely comparable to their 2SLS counterparts. Thus, weak instruments do not appear to be a concern.

\subsection{Assessing the exclusion Restriction: BaD Jobs or Bad COntractors?}

Our identification framework requires that contractors only systematically affect participant outcomes through their effect on job placements. ${ }^{35}$ This exclusion restriction appears highly plausible. Based on a detailed survey of Work First contractors in the Detroit area analyzed by this study (Autor and Houseman 2006), we document that program funding is tight and few resources are spent on anything but job placement. A standardized program of general or life skills training is provided in the first week of the program at all contractors. After the first week, all contractors focus on job placement. Support services intended to aid job retention, such as childcare and transportation, are equally available to participants from all contractors and are provided outside the program. Thus, there is little scope for contractors to substantially affect participant outcomes through any modality other than job placements.

As a further plausibility check on the exclusion restriction, we assess the importance of other contractor practices or impacts on participant outcomes that are not related to job placements. Referring to the reduced form version of our main estimating equation (7), we noted above the possibility that contractors may affect participant outcomes through practices that are uncorrelated with their placement rates (represented by $\nu_{c t}$ ). For example, contractors might provide counseling or support services that improve subsequent participant outcomes without directly affecting Work First job placements. This form of contractor heterogeneity is not intrinsically problematic for our identification strategy since it does not violate the identification assumption that contractor-by-year random effects are mean independent of contractor placement rates, i.e., $E\left(\nu_{c t} \bar{D}_{c t}\right)=E\left(\nu_{c t} \bar{T}_{c t}\right)$. If present, however, it would suggest that our main statistical model, focused on job placements, provides a limited empirical characterization of the channels by which contractors affect participant outcomes.

We evaluate the importance of non-placement heterogeneity among contractors by testing the hypothesis that the total effect of contractor assignments on participant outcomes is captured by contractor-by-year placement rates in temporary-help and direct-hire jobs. We first estimate equation

\footnotetext{
${ }^{35}$ To see the role of this exclusion restriction in our identification strategy, consider a hypothetical case in which Work First contractors who provide generally poor participants services also place a disproportionate share of their assigned participants in temporary help jobs. Further, assume that temporary help jobs have the same causal effect on employment and earnings as direct-hire jobs. In this case, our 2SLS estimates would misattribute the effect of receiving a bad contractor assignment to the effect of obtaining a temporary help job, leading to downward biased estimates of the causal effect of temporary-help placements on participant outcomes. Note that this scenario violates the exclusion restriction because it assumes that contractors systematically affect participant outcomes through practices that are correlated with but not caused by job placements, i.e., $E\left(\nu_{c t} \bar{T}_{c t}\right)<0$ or $E\left(\nu_{c t} \bar{D}_{c t}\right)>0$ or both (see equation 11$)$.
} 
(7) by OLS, using observed temporary-help and direct-hire placement rates $\left(\bar{D}_{c t}\right.$ and $\left.\bar{T}_{c t}\right)$ as the main explanatory variables. We then re-estimate equation (7), replacing the observed placement rates with a complete set of contractor-by-year dummy variables. An F-test comparing the sum of squared residuals from these two specifications tests whether the unrestricted model, containing 59 contractorby-year dummy variables, has significantly more explanatory power for participant outcomes than the restricted model in which these dummies are parameterized as $\bar{D}_{c t}$ and $\bar{T}_{c t}{ }^{36}$

This test yield a compelling result: we find no significant effects of contractor practices on participant outcomes that are not captured by temporary-help and direct-hire placement rates. Specifically, for both 8 quarter earnings and 8 quarter employment, we accept the null at the 42 and 15 percent level, respectively, that the 59 contractor-by-year dummy variables have no additional explanatory power for participant outcomes beyond simple mean contractor-by-year job placement rates in directhire and temporary-help jobs. Notably, this test has substantial power against the null. If we instead collapse the two separate job placement rate variables into a single measure that sums the two $\left(\bar{P}_{c t}=\bar{T}_{c t}+\bar{D}_{c t}\right)$, the F-test accepts the null at the 24 percent level (down from 42 percent) for 8 quarter earnings and rejects at the 4 percent level for 8 quarter employment. Thus, a parameterization that distinguishes between the causal effects of temporary-help and direct-hire placements is both necessary and sufficient to statistically capture the full effect of contractor assignments on participant outcomes. This result is consistent with the hypothesis that it is temporary-help and direct-hire job placements per se, rather than other contractor practices, that explain the sizable and robust effects of Work First contractor assignments on participant outcomes.

\section{INTERPRETING THE ESTIMATES}

In this final empirical section, we consider the interpretation of the results in light of the econometric framework. We first evaluate whether the Local Average Treatment Effect interpretation of the results is supported. We then explore the characteristics of the 'complier' group, whose Work First job placement is affected by contractor assignment and whose behavior thus identifies the effects of temporary-help and direct-hire placements on earnings and employment outcomes.

\footnotetext{
${ }^{36}$ There are 100 contractor-by-year cells and 40 district-by-year dummy variables plus an intercept. This leaves 59 contractor-by-year dummies as instruments. The F-test of these restrictions is distributed $F(J-M, N-J)$, where $N$ is the total count of observations, $J$ is the number of parameters in the unrestricted model, and $J-M$ is the number of parameters in the restricted model.
} 


\subsection{Testing the LATE assumptions}

A LATE interpretation of our results assumes that the instrumental variables impacting direct-hire placement are distinct from those variables impacting temporary-help placement (see section 2). We test this assumption here by independently estimating equation (6) for both endogenous employment variables (direct-hire, temporary-help) while using the full set of instrumental variables in each case. In particular, consider the following three alternative models for participant outcomes:

$$
\begin{aligned}
& Y_{i c d t}=\alpha_{1}+\beta_{1} D_{i}+\beta_{2} T_{i}+X_{i} \beta_{3}+\gamma_{d}+\phi_{t}+\theta_{d t}+\varepsilon_{i c d t} \\
& Y_{i c d t}=\alpha^{\prime}+\beta_{1}^{\prime} D_{i}+X_{i} \beta_{3}^{\prime}+\gamma_{d}^{\prime}+\phi_{t}^{\prime}+\theta_{d t}^{\prime}+\varepsilon_{i c d t}^{\prime} \\
& Y_{i c d t}=\alpha^{\prime \prime}+\beta_{2}^{\prime \prime} T_{i}+X_{i} \beta_{3}^{\prime \prime}+\gamma_{d}^{\prime \prime}+\phi_{t}^{\prime \prime}+\theta_{d t}^{\prime \prime}+\varepsilon_{i c d t}^{\prime \prime} .
\end{aligned}
$$

In the first equation, both endogenous placement variables (temporary-help and direct-hire) are included. In the second and third equations, only the direct-hire or temporary-help variable is included. The independence assumption implies that $\beta_{1}=\beta_{1}^{\prime}$ and $\beta_{2}=\beta_{2}^{\prime \prime}$, that is, the estimated causal effects of temporary-help and direct-hire placements on outcomes are invariant to whether these effects are estimated separately or jointly.

We test this implication by stacking three copies of the full data set (i.e., dependent and independent variables and instruments) and estimating a pooled model for outcomes over eight quarters that nests all three specifications while allowing for unrestricted error correlations among the estimates. ${ }^{37}$ Estimates, found in Appendix Table 3, are generally supportive of the independence assumptions. For both earnings and employment, we accept the null of the joint equality of the job placement coefficients with p-values of 0.22 and 0.20 respectively. ${ }^{38}$

Inspection of the Appendix Table 3 estimates does suggest, however, that the independence assumption is only approximately satisfied. In particular, 2SLS estimates of the impact of temporaryhelp placements on eight-quarter employment and earnings change from being weakly negative in specifications where the direct-hire dummy is included to being weakly positive in specifications where it is not. To explore the source of this sensitivity, we estimate the following model:

$$
\bar{D}_{c t}=\alpha+\varsigma \bar{T}_{c t}+\gamma_{d}+\phi_{t}+\theta_{d t}+\nu_{c t}+\omega_{c t} .
$$

Here, the dependent variable is the contractor-year placement rate in direct-hire jobs and the key independent variable is the contractor-year placement rate in temporary-help jobs. We obtain an estimate of $\hat{\varsigma}=0.32$ with a standard error of 0.15 . This indicates that contractors that have relatively

\footnotetext{
${ }^{37}$ This is akin to a Seemingly Unrelated Regression model estimated by 2SLS.

${ }^{38}$ We also accept the null hypothesis at least the 0.07 percent level for each pair of coefficients tested individually.
} 
high temporary-help placement rates also have relatively high direct-hire placement rates, and this relationship is modestly statistically significant. ${ }^{39}$ Accordingly, although the independence assumption is satisfied at conventional levels of significance, some caution is warranted in interpreting the 2SLS estimates within the LATE framework. As discussed in section 1, even if the conditions for a LATE interpretation are not met, our IV estimates still recover local treatment effects under the assumption that these effects are constant among the complier population - that is, under the assumption that the impact of temporary and direct-hire placements is constant among the subset of welfare participants whose job placement type is altered by contractor assignment.

\subsection{Who ARE THE MARGINAL TEMPORARY-HELP AND DIRECT-HIRE WORKERS?}

Under either the LATE or local constant effects interpretation, our 2SLS estimates identify the effect of direct-hire and temporary-help placements for participants whose Work First job placement is affected by contractor assignment. To interpret these estimates, it is valuable to assess how the characteristics of these compliers ('marginal workers') compare to the full set of job-takers in the Work First population, and, moreover, how the complier populations for the temporary-help and direct-hire treatments compare to one another.

To obtain estimates of the average characteristics of the complier populations we follow the approach proposed by Abadie (2002). Let $X$ be a predetermined participant characteristic of interest and $D$ and $T$ be a pair of dummy variables indicating whether a participant obtained a direct-hire job or a temporary-help placement during her Work First spell. Consider the following regression equation:

$$
\left[D_{i}+T_{i}\right] \cdot X_{i c d t}=\alpha+\kappa_{1} D_{i}+\kappa_{2} T_{i}+\gamma_{d}+\theta_{t}+\left(\gamma_{d} \times \theta_{t}\right)+\varepsilon_{i c d t},
$$

where, as before, subscripts $c, d$, and $t$ denote contractors, randomization districts, and year. By construction, the dependent variable is equal to $X_{i}$ if participant $i$ obtained employment during the Work First spell and zero otherwise. Estimated by OLS, the parameters $\hat{\kappa}_{1}$ and $\hat{\kappa}_{2}$ in equation (8) recover the (conditional) mean values of demographic variable $X$ for Work First participants who obtained direct-hire and temporary-help placements respectively during their Work First spells.

Table 8 summarizes OLS estimates of equation (8) for participants' earnings and employment, both overall and in temporary-help jobs, in the 8 quarters prior to their Work First placement. Participants who obtained direct-hire jobs during their Work First spell earned an average of $\$ 10,256$ and worked

\footnotetext{
${ }^{39}$ This result does provide further evidence, however, against the hypothesis that low-quality contractors tend to use temporary-help placements while high-quality contractors focus on direct-hire placements.
} 
4.47 quarters in the 8 calendar quarters prior to their contractor assignment (column 1). Prior earnings and employment for those who obtained temporary-help jobs are similar, equal to $\$ 10,457$ and 4.52 quarters respectively (see also Table 1). One difference between the two groups is also apparent. Participants who took temporary-help jobs during their Work First spell had approximately 60 to 70 percent higher earnings and employment in the temporary-help sector over the previous eight quarters than those who took direct-hire placements, and both contrasts are significant.

Now consider 2SLS estimates of equation (8), where the variables $T$ and $D$ are instrumented by contractor-by-year of assignment dummies. Here, $\hat{\kappa}_{1}$ and $\hat{\kappa}_{2}$ estimate the average characteristics $(X$ 's) of "marginal workers" - that is, participants whose employment status is changed by the rotational assignment (Abadie 2002, Lemma 2.1). To see this, consider a simplified example with only employment outcome, $J \in\{0,1\}$, and a single treatment variable, $Z \in\{0,1\}$, that affects the odds that a participant obtains employment $(J=1)$. Under standard LATE assumptions, a Wald estimate of Equation (8) yields the following quantity:

$$
\hat{\kappa}=\frac{E[X \mid J=1, Z=1] \cdot E[J \mid Z=1]-E[X \mid J=1, Z=0] \cdot E[J \mid Z=0]}{E[J \mid Z=1]-E[J \mid Z=0]} .
$$

The numerator of this expression is a scaled contrast between the average $X$ of employed participants in the treatment and control groups. The denominator rescales this contrast by the effect of the assignment to treatment on the probability of employment. The ratio of these two expressions provides an estimate of the average $X$ of compliers to the $Z$ treatment. ${ }^{40}$

Two stage least squares estimates of (8) yield two key results. First, the prior earnings histories of "marginal workers" are somewhat but not significantly weaker than those of average workers. Specifically, prior eight-quarter earnings and employment of marginal direct-hire workers are about $\$ 200$ and 0.12 quarters below those of average direct-hire workers while earnings and employment of marginal temporary-help workers are about $\$ 1,750$ and 0.40 quarters below those of average temporaryhelp workers. Hausman tests (bottom row of each panel) do not, however, reject the null of the equality of OLS and 2SLS estimates. Thus, the gap in earnings histories between marginal and average Work First participants who find employment during their Work First spells is not particularly stark. By

\footnotetext{
${ }^{40} \mathrm{~A}$ simple numerical example of the Abadie estimator illustrates. Let $X$ be a dummy variable equal to one if a participant is a high-school dropout and zero otherwise. Assume that 20 percent of treated participants and 10 percent of control participants find jobs during their Work First spells. Also assume that 70 percent of treated participants who find jobs are high school dropouts versus 50 percent of untreated participants. Using the above equation, these numbers imply that 90 percent of marginally employed are high school dropouts. The intuition for this result is that the marginal 10 percent of employed participants must be composed of 90 percent high school dropouts to raise the average high school dropout share among employed from 50 to 70 percent among the treated group. The fact that there are two treatments (temporary-help and direct-hire) in our application does not change the interpretation of the Abadie estimator so long as these treatments can be viewed as independent LATEs.
} 
implication, marginal participants have somewhat better earnings histories than average Work First participants who do not find employment during their Work First spells. In particular, Table 1 shows that participants who do not find employment during their Work First spells averaged $\$ 8,116$ in earnings and 3.83 quarters of employment in the 8 quarters prior to assignment. Both values are lower than the corresponding estimates for marginal workers. In short, marginal workers appear slightly less motivated or work-capable than average workers but slightly more motivated or work-capable than average non-workers.

The second main result of Table 8 is that there are no significant differences between the preassignment work histories of marginal temporary-help and marginal direct-hire workers. This result is most striking in the case of prior temporary-help employment and earnings. While the average participant taking a temporary-help job has significantly higher prior temporary-help earnings and employment than the average participant taking a direct-hire job, there is no statistically or economically significant difference between the temporary-help employment and earnings of marginal workers taking temporary-help and direct-hire jobs.

Both of the Table 8 results bear on the interpretation of our findings. The rough comparability in earnings histories between marginal and average workers obtaining job placements during their Work First spells suggests that our estimates recover causal effects estimates for a relevant complier population - one that is slightly but not significantly less motivated or work-capable than average Work First participants. As critically, the comparability between the earnings histories of marginal temporary-help and marginal direct-hire participants indicates that the causal effects of direct-hire and temporary-help placements are estimated on similar complier populations. By implication, the marginal temporary-help workers in our sample would likely have fared significantly better in terms of subsequent employment and earnings had they instead been placed into direct-hire jobs, while the marginal direct-hire workers in the analysis would likely have fared worse had they instead been placed into temporary-help jobs.

\section{Conclusion}

The primary finding of our analysis is that direct-hire placements induced by the rotational assignment of low-skilled workers to Work First contractors significantly increase payroll earnings and quarters of employment for marginal participants by two to three thousand dollars per year over the subsequent one, two and three years. Although temporary-help placements significantly raise employment and 
earnings in the temporary-help sector in the first year following contractor assignment, they crowd out employment and earnings in direct-hire jobs by roughly equal amounts, yielding a net effect that is statistically and economically close to zero. Thus, despite much descriptive evidence to the contrary, our analysis indicates that temporary-help placements have no beneficial or detrimental effect on earnings, employment or labor market advancement of low-skilled workers over any significant timespan.

These findings are pertinent to the economics literature on active labor market programs designed to improve employment and earnings among low-skilled workers. Large-scale random assignment experiments conducted with welfare-to-work and adult disadvantaged populations in the 1990s generally found that, compared to more costly intervention strategies, job placement services were as effective or more effective at improving subsequent labor market outcomes. In addition, on-going random assignment experiments at 15 sites in eight states are currently assessing the efficacy of various strategies that are intended to address persistent problems of job instability and lack of advancement in the welfare population (Bloom et al. 2005). While studies in this vein typically assess the net effect of various program features - in addition to job search assistance - on Work First participant outcomes, our study is the only analysis of which we are aware that directly assesses causal effects of job placement on recipients who receive them. ${ }^{41}$ This distinction proves important here. Although, consistent with the experimental literature, we find that job placements on average significantly improve long-term employment and earnings outcomes, our analysis also reveals that the benefits of job placement services derive entirely from placements into direct-hire jobs, which significantly improve job stability and the probability of on-going employment over the subsequent two years. Temporary-help placements, which comprise fully one in five job placements in our Work First sample, do not foster transitions to direct-hire jobs or improve any measure of job stability. Placements into temporary-help jobs are thus no more effective in raising earnings and labor force participation than is providing no placements at all—at least in the Work First setting that we study.

We emphasize that our results pertain to the marginal temporary-help job placements induced by the randomization of Work First participants across contractors, and therefore do not preclude the possibility that infra-marginal temporary-help placements generate significant benefits. Nevertheless,

\footnotetext{
${ }^{41}$ Bloom et al. (1997) summarizes the results from 16 random assignment studies of the efficacy of services provided to participants in JTPA Title II-A programs, which serviced disadvantaged adults. Table 4 of that study compares the estimated effects of programs that rely on classroom training compared to programs that provide job placement and on the job training services. Bloom and Michalopoulos (2001) summarize the results from a series of studies of welfare initiatives, all of which used random assignment research designs. These studies included analysis of the impact on annual earnings of programs that emphasized job-search-first and programs emphasizing education first.
} 
these findings are particularly germane for the design of welfare programs. The operative question for program design is whether job programs assisting welfare and other low-wage workers can improve participants' labor market outcomes by placing more clients in temporary agency positions. Our analysis suggests not. While participants placed in direct-hire jobs benefit substantially, workers induced to take temporary jobs by contractor assignments are no better off than they would have been without any job placement. This suggests that putting greater emphasis on placing participants in direct-hire jobs is a more promising approach for increasing earnings and employment stability in this population. 


\section{References}

Abadie, Alberto. 2002. "Bootstrap Tests for Distributional Treatment Effects in Instrumental Variables Models." Journal of the American Statistical Association, 97(457), March: 284-292.

Abraham, Katharine G. 1988. "Flexible Staffing Arrangements and Employers' Short-term Adjustment Strategies." In Employment, Unemployment, and Labor Utilization, Robert A. Hart, ed. Boston: Unwin Hyman.

Amuedo-Dorantes, Catalina, Miguel A. Malo, and Fernando Muñoz-Bullón. 2005. "The Role of Temporary Help Agencies on Workers' Career Advancement.” Unpublished working paper. San Diego State University, San Diego, CA.

Andersson, Pernilla, and Eskil Wadensjö. 2004. "Temporary Employment Agencies: A Route for Immigrants to Enter the Labour Market?" IZA Discussion Paper 1090. Bonn, Germany: Institute for the Study of Labor.

Andersson, Fredrik, Harry J. Holzer, and Julia I. Lane. 2005. Moving Up or Moving On: Who Advances in the Labor Market? New York: Russell Sage.

Andersson, Fredrik, Harry J. Holzer, and Julia I. Lane. 2007. "Temporary Help Agencies and the Advancement Prospects of Low Earners." NBER Working Paper No. 13434, September.

Angrist, Joshua D., Guido W. Imbens and Alan B. Krueger. 1999. "Jacknife Instrumental Variables Estimation." Journal of Applied Econometrics, 14(1): 57-67.

Autor, David H. 2001. "Why Do Temporary Help Firms Provide Free General Skills Training?" Quarterly Journal of Economics 116(4): 1409-1448.

Autor, David H. 2003. "Outsourcing at Will: The Contribution of Unjust Dismissal Doctrine to the Growth of Employment Outsourcing." Journal of Labor Economics 21(3): 1-42.

Autor, David H., and Susan N. Houseman 2002a. "Do Temporary Help Jobs Improve Labor Market Outcomes? A Pilot Analysis with Welfare Clients." MIT mimeograph. Cambridge, MA.

_ 2002b. "The Role of Temporary Employment Agencies in Welfare to Work: Part of the Problem or Part of the Solution?" Focus 22(1): 63-70.

—. 2006. "Temporary Agency Employment as a Way Out of Poverty?" In Rebecca Blank, Sheldon Danziger, and Robert Schoeni (eds), Working but Poor: How Economic and Policy Changes are Affecting Low-Wage Workers. New York: Russell Sage Foundation.

Benner, Chris, Laura Leete and Manuel Pastor. 2007. Staircases or Treadmills? Labor Market Intermediaries and Economic Opportunity in a Changing Economy. New York: Russell Sage Founda- 
tion.

Blanchard, Olivier, and Augustin Landier. 2002. "The Perverse Effects of Partial Labour Market Reform: Fixed-Term Contracts in France." Economic Journal 112(480): F214-F244.

Bloom, Howard S., Larry L. Orr, Stephen H. Bell, George Cave, Fred Doolittle, Winston Lin, and Johannes M. Bos . 1997. "The Benefits and Costs of JTPA Title II-A Programs: Findings from the National JTPA Study." Journal of Human Resources. 32(3): 549-576.

Bloom, Dan, Richard Hendra, Karin Martinson, and Susan Scrivener. 2005. The Employment Retention and Advancement Project: Early Results from Four Sites. New York: Manpower Research Demonstration Corporation.

Bloom, Dan and Charles Michalopoulos. 2001. How Welfare and Work Policies Affect Employment and Income: A Synthesis of Research. New York: Manpower Research Demonstration Corporation.

René Böheim and Ana Rute Cardoso. 2007. "Temporary help services employment in Portugal, 1995-2000.” NBER Working Paper No. 13582, November.

Booth, Alison L., Marco Francesconi, and Jeff Frank. (2002). "Temporary Jobs: Stepping Stones or Dead Ends?" Economic Journal 112(480): F189-F213.

Bound, John, David A. Jaeger and Regina Baker. 1995. "Problems with Instrumental Variables Estimation When the Correlation between the Instruments and the Endogenous Explanatory Variable Is Weak." Journal of the American Statistical Association, 90(430): 443-450.

Cancian, Maria, Robert Haveman, Thomas Kaplan, and Barbara Wolfe. 1999. Post-Exit Earnings and Benefit Receipt among Those Who Left AFDC in Wisconsin. Madison, WI: Institute for Research on Poverty, University of Wisconsin-Madison.

Card, David and Dean Hyslop R. 2005. "Estimating the Effects of a Time-Limited Earnings Subsidy for Welfare-Leavers." Econometrica, 73(6), November: 1723-1770.

Corcoran, Mary, and Juan Chen. 2004. "Temporary Employment and Welfare-to-Work." Unpublished paper, University of Michigan, Ann Arbor, MI.

DiNatale, Marisa. 2001. "Characteristics and Preference for Alternative Work Arrangements, 1999." Monthly Labor Review 124(3): 28-49.

Doyle, Joseph J. Jr. 2007. "Child Protections and Child Outcomes: Measuring the Effect of Foster Care." American Economic Review 97(5): 1583-1610.

Ferber, Marianne A., and Jane Waldfogel. 1998. "The Long-Term Consequences of Nontraditional Employment." Monthly Labor Review 121(5): 3-12. 
García-Pérez, J. Ignacio, and Fernando Muñoz-Bullón. 2002. "The Nineties in Spain: Too Much Flexibility in the Labor Market?" Unpublished working paper, Universidad Carlos III de Madrid.

General Accounting Office (GAO). 2000. "Contingent Workers: Incomes and Benefits Lag Behind the Rest of the Workforce." GAO/HEHS-00-76, Washington, DC: GAO. http://www.gao.gov/ (accessed September 23, 2005).

Gerfin, Michael, Michael Lechner, and Heidi Steiger. 2005. "Does Subsidized Temporary Employment Get the Unemployed Back to Work? An Econometric Analysis of Two Different Schemes." Labour Economics 12(6): 807-835.

Heinrich, Carolyn J., Peter R. Mueser, and Kenneth R. Troske. 2005. "Welfare to Temporary Work: Implications for Labor Market Outcomes." Review of Economics and Statistics 87(1): 154173.

—. "The Role of Temporary-help Employment in Low-Wage Worker Advancement." NBER Working Paper No. 13520, October 2007.

Houseman, Susan N. 2001. "Why Employers Use Flexible Staffing Arrangements: Evidence from an Establishment Survey." Industrial and Labor Relations Review 55(1): 149-170.

Houseman, Susan N., Arne J. Kalleberg, and George A. Erickcek. 2003. "The Role of Temporary Help Employment in Tight Labor Markets." Industrial and Labor Relations Review 57(1): 105-127.

Ichino, Andrea, Fabrizia Mealli, and Tommaso Nannicini. 2005. "Temporary Work Agencies in Italy: A Springboard to Permanent Employment?" Giornale degli Economisti 64 (1): 1-27.

—. forthcoming. "From Temporary Help jobs to Permanent Employment: What Can We Learn from Matching Estimators and their Sensitivity?" Journal of Applied Econometrics.

Imbens, Guido W., and Joshua D. Angrist. 1994. "Identification and Estimation of Local Average Treatment Effects." Econometrica 62(2): 467-475.

Jorgenson, Helene, and Hans Riemer. 2000. "Permatemps: Young Temp Workers as Permanent Second Class Employees." American Prospect 11(18): 38-40.

Kalleberg, Arne L., Jeremy Reynolds, and Peter V. Marsden. 2003. "Externalizing Employment: Flexible Staffing Arrangements in U.S. Organizations." Social Science Research 32: 525-552.

Kvnasnicka, Michael. 2007. "Does Temporary Help Work Provide a Stepping Stone to Regular Employment?" NBER Working Paper.

Katz, Lawrence F., and Alan B. Krueger. 1999. "The High-Pressure U.S. Labor Market of the 1990s." Brookings Papers on Economic Activity 0(1): 1-65. 
Kling, Jeffrey R. 2005. "Incarceration Length, Employment, and Earnings." American Economic Review, 96(3), June: 863-876.

Kling, Jeffrey R., Jeffrey B. Liebman, and Lawrence F. Katz. 2007. "Experimental Analysis of Neighborhood Effects on Youth." Econometrica 75(1), January: 83-199.

Lane, Julia, Kelly S. Mikelson, Pat Sharkey, and Doug Wissoker. 2003. "Pathways to Work for Low-Income Workers: The Effect of Work in the Temporary Help Industry." Journal of Policy Analysis and Management 22(4): 581-598.

Parker, Robert E. 1994. Flesh Peddlers and Warm Bodies: The Temporary Help Industry and Its Workers. New York: Rutgers University Press.

Pawasarat, John. 1997. "The Employer Perspective: Jobs Held by the Milwaukee County AFDC Single Parent Population (January 1996-March 1997)." Milwaukee: Employment and Training Institute, University of Wisconsin-Milwaukee.

Segal, Lewis M., and Daniel G. Sullivan. 1997. "The Growth of Temporary Services Work." Journal of Economic Perspectives 11: 117-136.

—. 1998. "Wage Differentials for Temporary Services Work: Evidence from Administrative Data." Federal Reserve Bank of Chicago Working Paper No. 98-23.

U.S. Department of Labor, Bureau of Labor Statistics. 2005. "News Release USDL 05-1433: Contingent and Alternative Employment Arrangements, February 2005” available at www.bls.gov/news.release/pdf/conemp.pdf, accessed 12/24/2007.

Zijl, Marleos, Gerard J. van den Berg, and Arjan Hemya. 2004. "Stepping Stones for the Unemployed: The Effect of Temporary Jobs on the Duration until Regular Work." IZA Discussion Paper No. 1241. Bonn, Germany: Institute for the Study of Labor. 
Figure 1. Research Design

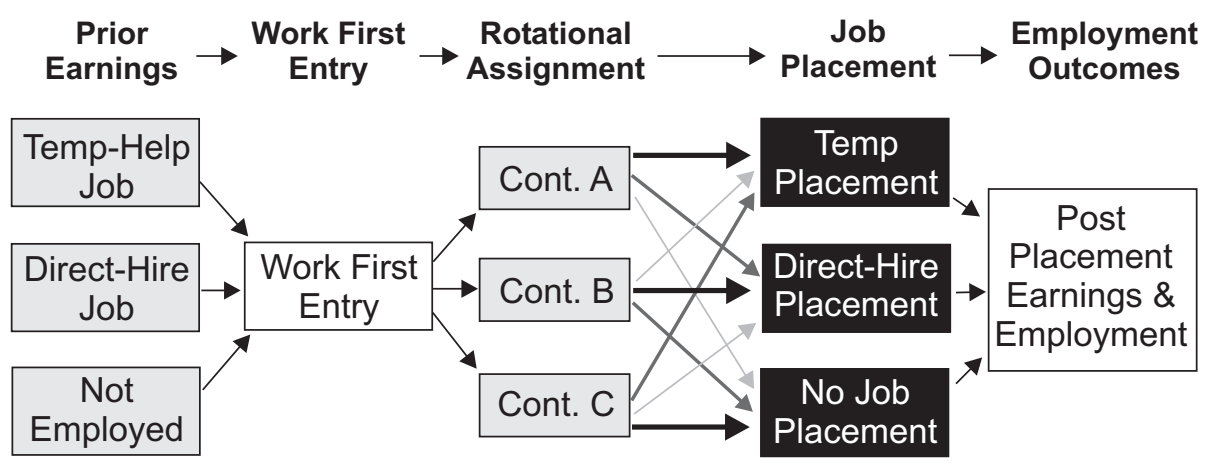



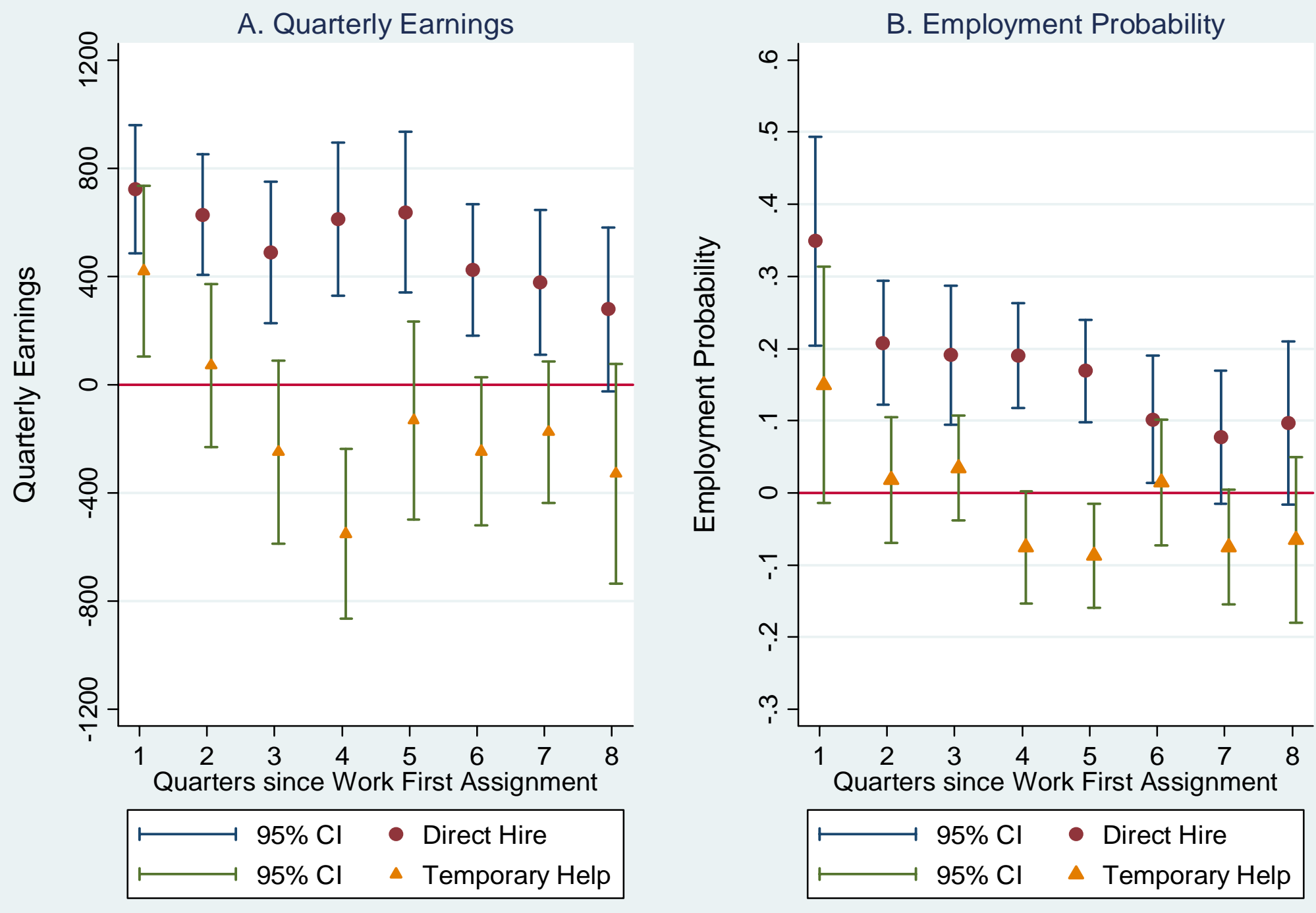

Figure 2. Two-Stage Least Squares Estimates of the Effect of Direct-Hire and Temporary-Help J ob Placements on Quarterly Earnings and Probability of Employment in Quarters 1 through 8 Following Work First Contractor Assignment.

Notes. Each pair of plotted points is from a separate 2SLS regressions of the indicated outcome variable for the relevant quarter on the direct-hire and temporary-help job placements instrumented by contractor-by-year of assignment. Confidence intervals are estimated with robust standard errors that are clustered on contractor assignment. Details of samples and control variables are given in Table 4. 
A. Baseline: Participants with No Job Placement

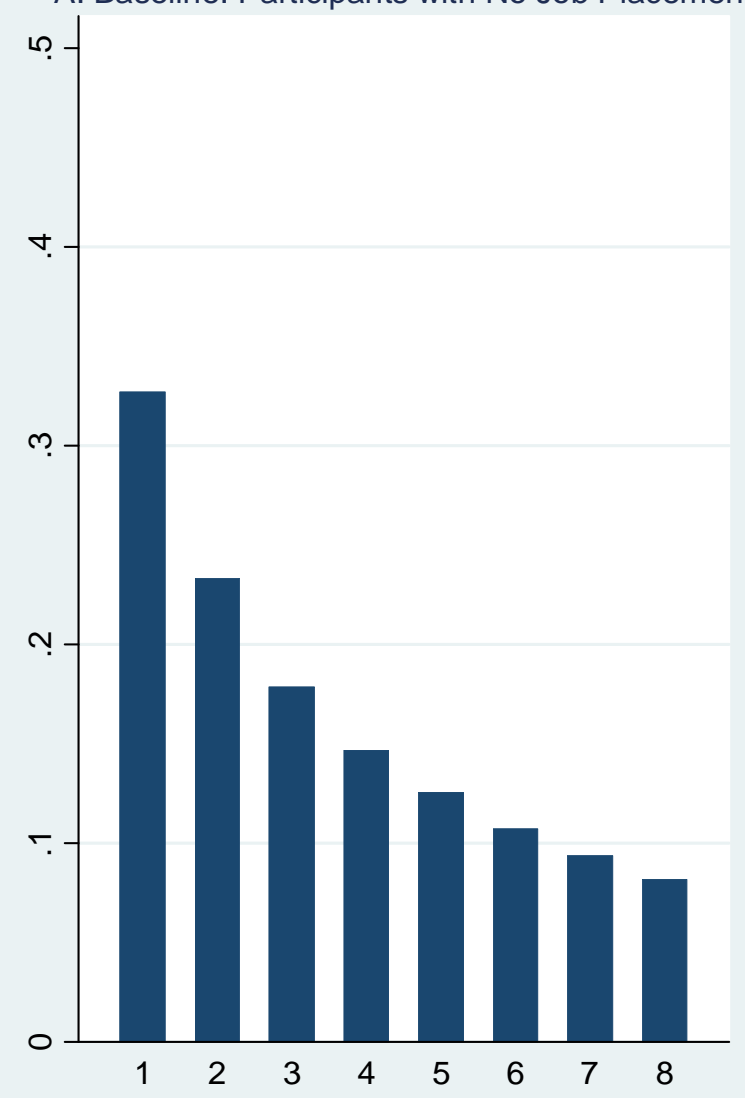

B. Causal Effect on Survival Probability

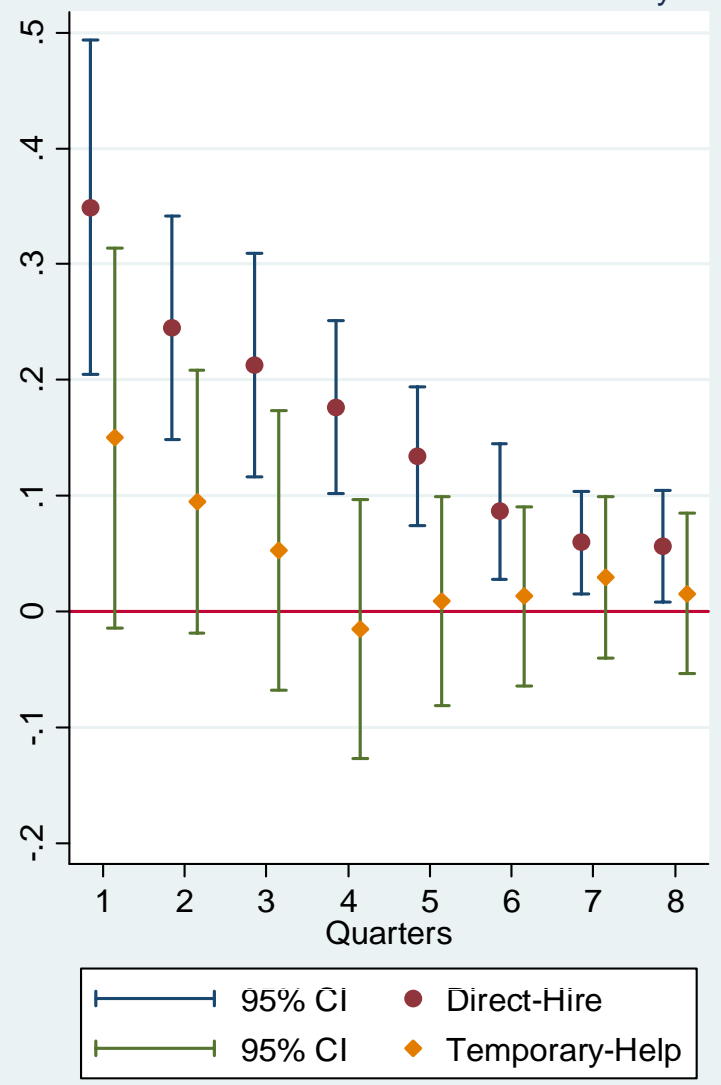

Figure 3. Two-Stage Least Squares Estimates of the Effect of Direct-Hire and Temporary-Help J ob Placements on Survivor Probability in Ongoing Employment: $\operatorname{Pr}[$ J ob Spell>=Q].

Notes. Height of first quarter bar in panel A equals the unconditional probability of employment in quarter 1 following contractor assignment for participants receiving no placement during their Work First spell. Subsequent bars depict the survival probability in ongoing employment for non-placed participants obtaining employment in first quarter. Similarly, height of first quarter point estimate in panel $B$ equals the causal effect of job placement during Work First spell on the probability of employment in quarter 1 following contractor assignment (relative to participants who are not placed). Subsequent point estimates depict causal effects on survival probabilities in ongoing employment for participants receiving placements during the Work First spell (relative to those not placed). 

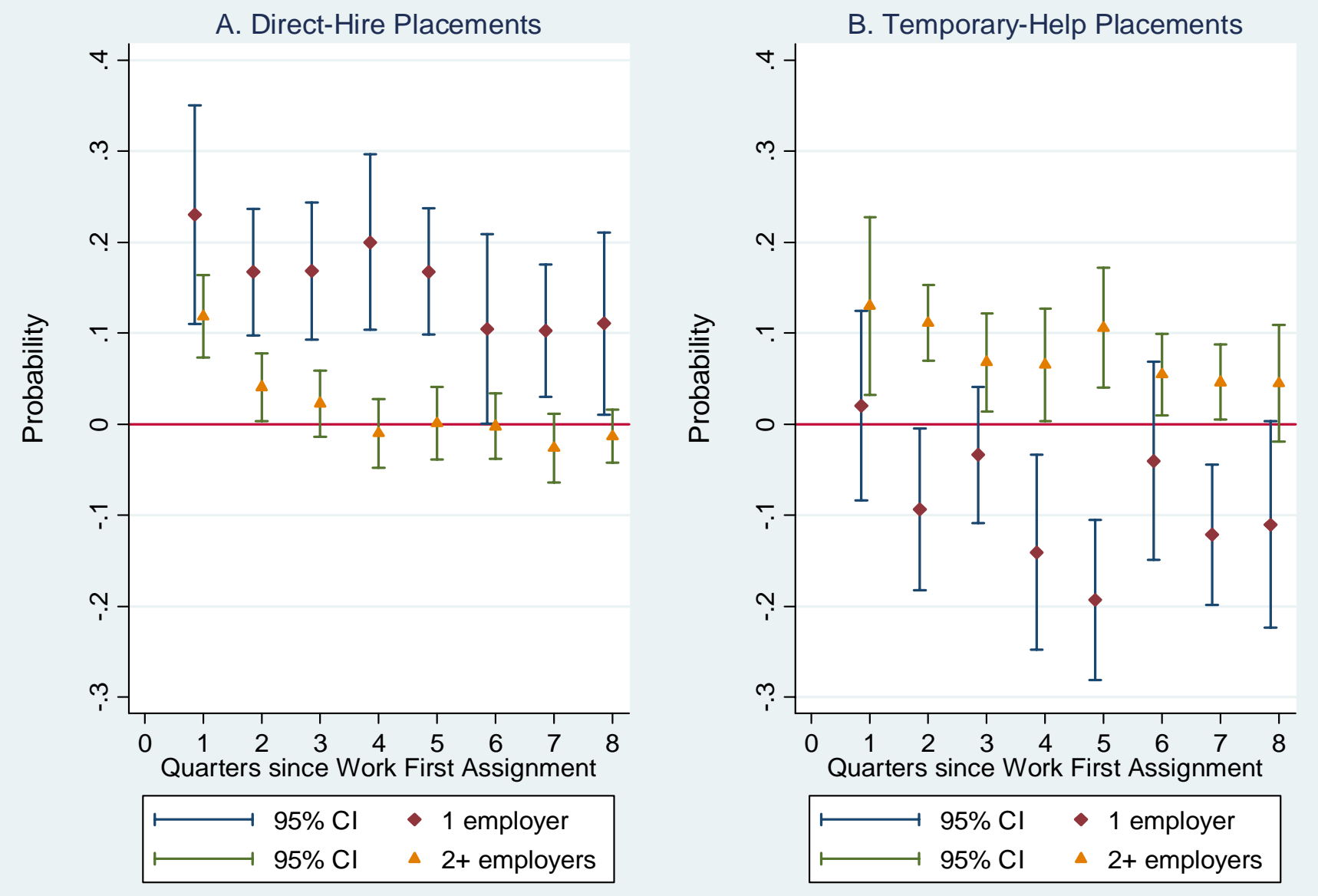

Figure 4. Two-Stage Least Squares Estimates of the Effect of Direct-Hire and Temporary-Help J ob Placements on Probability of Holding One or Two-Plus J obs in each of Eight Post-Assignment Quarters.

Notes. Estimates for each outcome (one employer, two-plus employers) are from separate 2SLS regressions of the indicated outcome variable for the relevant quarter on the direct-hire and temporary-help job placements instrumented by contractor-by-year of assignment. Confidence intervals are estimated with robust standard errors that are clustered on contractor assignment. Details of samples and control variables are given in Table 4. 
Table 1

Summary Statistics for Primary Sample of Detroit Work First Participants Assigned to Contractors in $1999-2003$

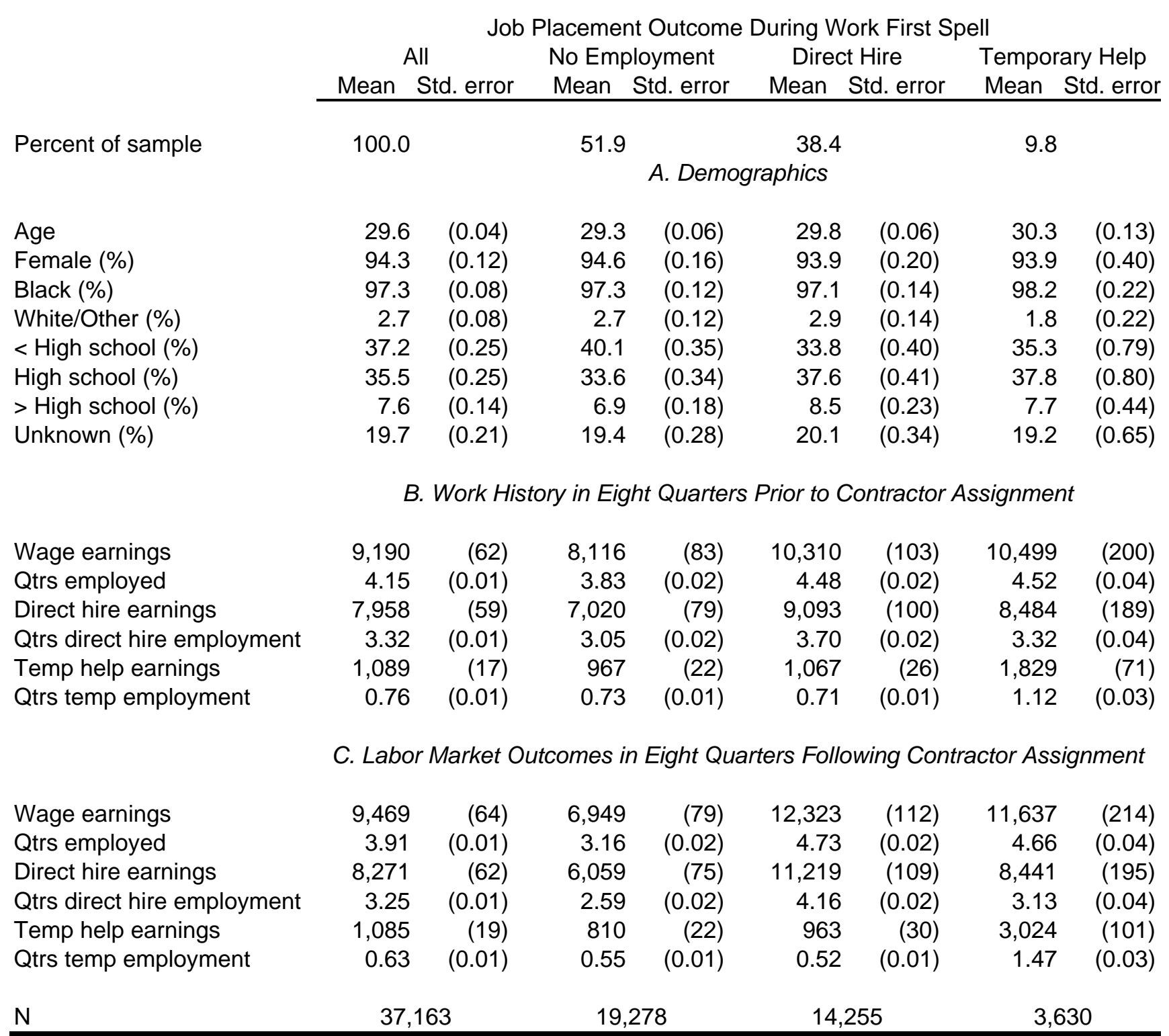

Sample is comprised of all Work First spells initiated from the fourth quarter of 1999 through the first quarter of 2003 in 12 Work First assignment districts in Detroit, Michigan. Data source is Detroit administrative records data from Work First programs linked to quarterly earnings from Michigan unemployment insurance wage records. Job placement outcomes and hourly earnings during Work First spell are coded using Detroit administrative records. Quarterly temporary-help and direct-hire earnings in eight quarters pre and post contractor assignment are coded using state of Michigan unemployment insurance records, where employer type is determined by industry codes. Work First Participants may have multiple spells. All earnings are inflated to 2003 dollars using the Consumer Price Index (CPI-U). 
Table 2

OLS Estimates of the Relationship between Work First Job Placements and Subsequent Earnings and Quarters of Employment One to Eight Quarters Following Work First Assignment: Participants Assigned 1999 - 2003

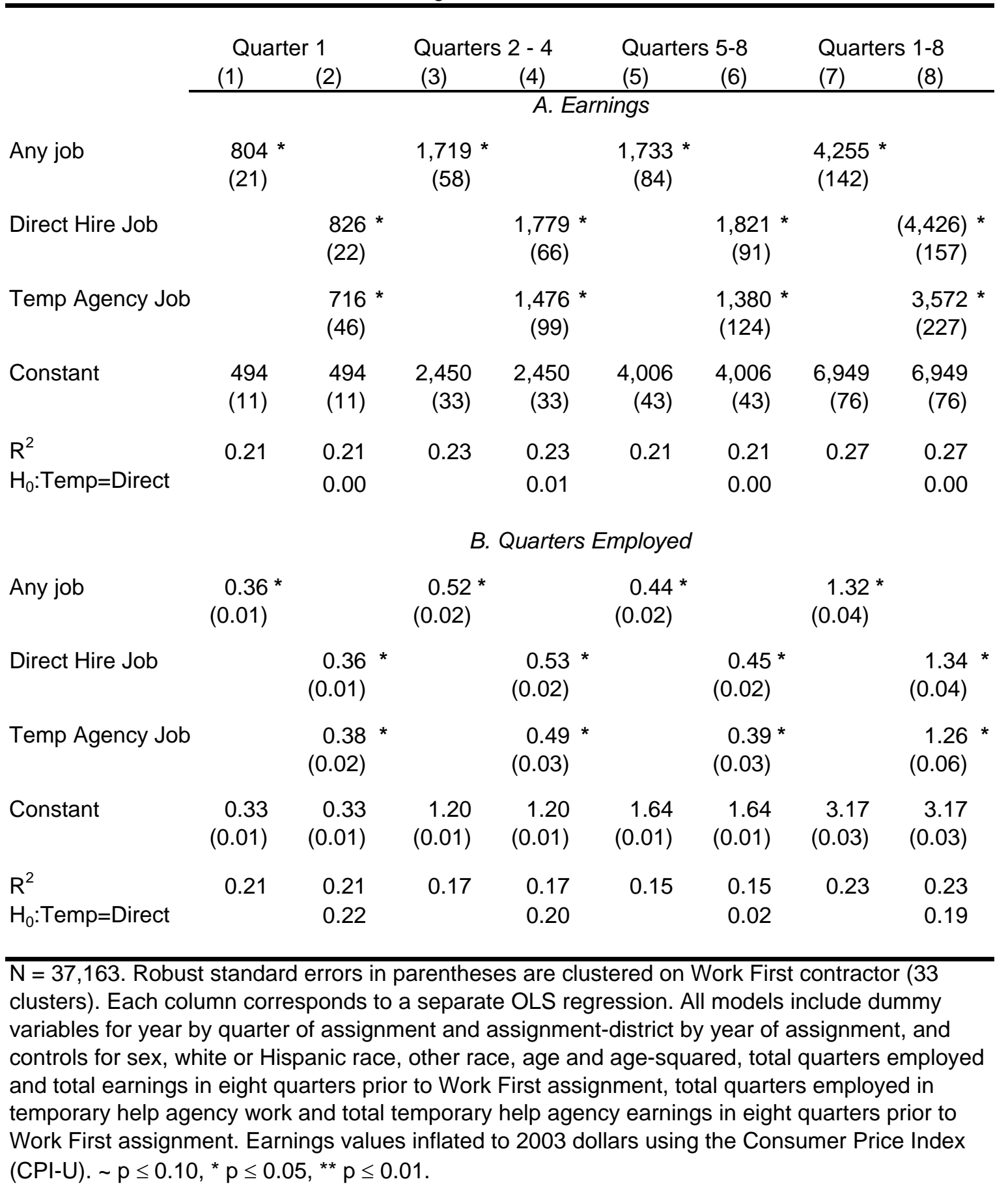


Table 3

Instrumental Variables Estimates of The Effect of Work First Job Placements on Subsequent Earnings and Quarters of Employment One to Eight Quarters Following Work First Assignment: Participants Assigned 1999 - 2003

\begin{tabular}{|c|c|c|c|c|c|c|c|c|}
\hline & \multicolumn{2}{|c|}{ Quarter 1} & \multicolumn{2}{|c|}{ Quarters 2 - 4} & \multicolumn{2}{|c|}{ Quarters 5-8 } & \multicolumn{2}{|c|}{ Quarters 1-8 } \\
\hline & (1) & $(2)$ & (3) & $(4)$ & (5) & $(6)$ & (7) & (8) \\
\hline & \multicolumn{8}{|c|}{ A. Earnings } \\
\hline Any job & \multicolumn{2}{|l|}{$\begin{array}{l}621 \text { * } \\
(143)\end{array}$} & \multirow[t]{2}{*}{$\begin{array}{r}904 \\
(323)\end{array}$} & & \multirow[t]{2}{*}{$\begin{array}{r}845 \text { * } \\
(397)\end{array}$} & & \multicolumn{2}{|c|}{$\begin{array}{l}2,370 * \\
(791)\end{array}$} \\
\hline Direct Hire Job & & $\begin{array}{l}722 \text { * } \\
(161)\end{array}$ & & $\begin{array}{l}1,731 \text { * } \\
(454)\end{array}$ & & $\begin{array}{l}1,720 \text { * } \\
(621)\end{array}$ & & $\begin{array}{c}4,173 \text { * } \\
(1,175)\end{array}$ \\
\hline Temp Agency Job & & $\begin{array}{l}420 \text { * } \\
(206)\end{array}$ & & $\begin{array}{l}-729 \sim \\
(386)\end{array}$ & & $\begin{array}{r}-882 \\
(583)\end{array}$ & & $\begin{array}{r}-1,190 \\
(999)\end{array}$ \\
\hline Constant & $\begin{array}{l}579 \\
(65)\end{array}$ & $\begin{array}{l}560 \\
(65)\end{array}$ & $\begin{array}{l}2,829 \\
(142)\end{array}$ & $\begin{array}{l}2,673 \\
(166)\end{array}$ & $\begin{array}{l}4,419 \\
(182)\end{array}$ & $\begin{array}{l}4,254 \\
(227)\end{array}$ & $\begin{array}{l}7,827 \\
(353)\end{array}$ & $\begin{array}{l}7,487 \\
(426)\end{array}$ \\
\hline $\begin{array}{l}\mathrm{R}^{2} \\
\mathrm{H}_{0}: \text { Temp=Direct }\end{array}$ & 0.21 & $\begin{array}{l}0.21 \\
0.20\end{array}$ & 0.22 & $\begin{array}{l}0.21 \\
0.00\end{array}$ & 0.20 & $\begin{array}{l}0.20 \\
0.01\end{array}$ & 0.26 & $\begin{array}{l}0.25 \\
0.00\end{array}$ \\
\hline & \multicolumn{8}{|c|}{ B. Quarters Employed } \\
\hline Any job & \multicolumn{2}{|l|}{$\begin{array}{l}0.28 \text { * } \\
(0.06)\end{array}$} & \multicolumn{2}{|l|}{$\begin{array}{c}0.38 \text { * } \\
(0.09)\end{array}$} & $\begin{array}{l}0.22 \text { * } \\
(0.11)\end{array}$ & & \multicolumn{2}{|c|}{$\begin{array}{l}0.89 \text { * } \\
(0.23)\end{array}$} \\
\hline Direct Hire Job & & $\begin{array}{r}0.35 * \\
(0.07)\end{array}$ & & $\begin{array}{c}0.59 \\
(0.12)\end{array}$ & & $\begin{array}{c}0.45 \text { * } \\
(0.17)\end{array}$ & & $\begin{array}{r}1.38 \text { * } \\
(0.34)\end{array}$ \\
\hline Temp Agency Job & & $\begin{array}{r}0.15 \sim \\
(0.08)\end{array}$ & & $\begin{array}{l}-0.02 \\
(0.09)\end{array}$ & & $\begin{array}{l}-0.21 \\
(0.15)\end{array}$ & & $\begin{array}{l}-0.09 \\
(0.23)\end{array}$ \\
\hline Constant & $\begin{array}{r}0.36 \\
(0.03)\end{array}$ & $\begin{array}{r}0.35 \\
(0.03)\end{array}$ & $\begin{array}{r}1.26 \\
(0.04)\end{array}$ & $\begin{array}{r}1.22 \\
(0.05)\end{array}$ & $\begin{array}{r}1.74 \\
(0.05)\end{array}$ & $\begin{array}{r}1.70 \\
(0.06)\end{array}$ & $\begin{array}{r}3.37 \\
(0.10)\end{array}$ & $\begin{array}{r}3.27 \\
(0.12)\end{array}$ \\
\hline $\begin{array}{l}\mathrm{R}^{2} \\
\mathrm{H}_{0}: \text { Temp=Direct }\end{array}$ & 0.21 & $\begin{array}{l}0.19 \\
0.09\end{array}$ & 0.17 & $\begin{array}{l}0.16 \\
0.00\end{array}$ & 0.15 & $\begin{array}{l}0.14 \\
0.02\end{array}$ & 0.22 & $\begin{array}{l}0.21 \\
0.00\end{array}$ \\
\hline \multicolumn{9}{|c|}{$\begin{array}{l}\mathrm{N}=37,163 \text {. Robust standard errors in parentheses are clustered on Work First contractor ( } 33 \\
\text { clusters). Each column corresponds to a separate } 2 \text { SLS regression. Instrumental variables for jobs } \\
\text { obtained (any, direct-hire and temporary-help) are contractor by year of assignment dummies. All } \\
\text { models include dummy variables for year by quarter of assignment and assignment-district by year } \\
\text { of assignment, and controls for sex, white or Hispanic race, other race, age and age-squared, total } \\
\text { quarters employed and total earnings in eight quarters prior to Work First assignment, total quarters } \\
\text { employed in temporary help agency work and total temporary help agency earnings in eight } \\
\text { quarters prior to Work First assignment. Earnings values inflated to } 2003 \text { dollars using the } \\
\text { Consumer Price Index (CPI-U). } \sim p \leq 0.10,{ }^{*} p \leq 0.05,{ }^{* *} p \leq 0.01 \text {. }\end{array}$} \\
\hline
\end{tabular}


Table 4

The Effect of Work First Job Placements on Subsequent Earnings and Quarters of Employment One to Twelve Quarters Following Work First Assignment: Participants Assigned 1999 - 2002

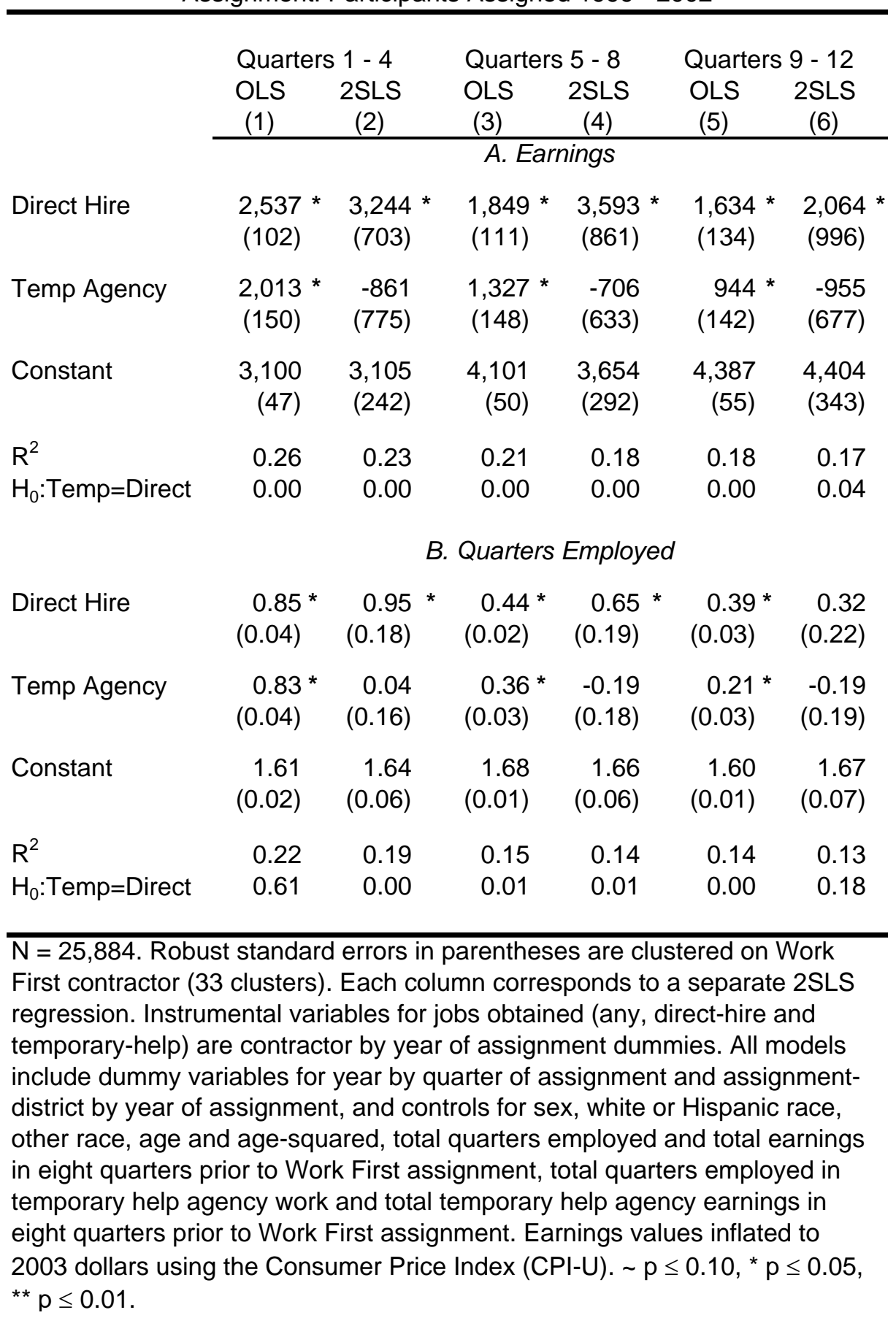




\section{Table 5}

2SLS Estimates of the Effect of Work First Job Placements on Quarters Employed and Earnings in Longest Continuous Work Spell and Longest Continuous Spell with a Single Employer during Eight Quarters Following Work First Assignment

\begin{tabular}{|c|c|c|c|c|c|c|}
\hline & $\begin{array}{l}\text { All } \\
(1)\end{array}$ & $\begin{array}{c}\text { Longest } \\
\text { Spell } \\
(2)\end{array}$ & $\begin{array}{c}\text { Longest } \\
\text { Job } \\
(3) \\
\end{array}$ & $\begin{array}{l}\text { All } \\
(1) \\
\end{array}$ & $\begin{array}{l}\text { ongest } \\
\text { Spell } \\
(2) \\
\end{array}$ & $\begin{array}{c}\text { Longest } \\
\text { Job } \\
(3)\end{array}$ \\
\hline & \multicolumn{3}{|c|}{ A. Earnings } & \multicolumn{3}{|c|}{ B. Quarters Employed } \\
\hline Direct Hire Job & $\begin{array}{c}4,173 \text { * } \\
(1,175)\end{array}$ & $\begin{array}{c}3,885 \text { * } \\
(1,055)\end{array}$ & $\begin{array}{c}3,107 \text { * } \\
(1,001)\end{array}$ & $\begin{array}{l}1.38 \text { * } \\
(0.34)\end{array}$ & $\begin{array}{l}1.07 \text { * } \\
(0.27)\end{array}$ & $\begin{array}{c}0.92 \text { * } \\
(0.29)\end{array}$ \\
\hline Temp Agency Job & $\begin{array}{r}-1,190 \\
(999)\end{array}$ & $\begin{array}{r}-1,509 \\
(966)\end{array}$ & $\begin{array}{c}-1,966 \text { * } \\
(832)\end{array}$ & $\begin{array}{r}-0.09 \\
(0.23)\end{array}$ & $\begin{array}{l}-0.09 \\
(0.21)\end{array}$ & $\begin{array}{l}-0.22 \\
(0.20)\end{array}$ \\
\hline Constant & $\begin{array}{l}7,487 \\
(426)\end{array}$ & $\begin{array}{l}6,984 \\
(378)\end{array}$ & $\begin{array}{l}5,734 \\
(347)\end{array}$ & $\begin{array}{r}3.27 \\
(0.12)\end{array}$ & $\begin{array}{r}2.88 \\
(0.10)\end{array}$ & $\begin{array}{r}2.28 \\
(0.10)\end{array}$ \\
\hline $\mathrm{R}^{2}$ & 0.25 & 0.24 & 0.20 & 0.21 & 0.19 & 0.15 \\
\hline $\mathrm{H}_{\mathrm{o}}:$ Temp = Direct & 0.00 & 0.00 & 0.00 & 0.00 & 0.00 & 0.01 \\
\hline
\end{tabular}

$\mathrm{N}=37,163$. Robust standard errors in parentheses are clustered on Work First contractor (33 clusters). Each column corresponds to a separate 2SLS regression. An employment spell is a set of contiguous quarters of positive earnings, and a job spell is a set of contiguous quarters with earnings from the same employer. Where participants have multiple jobs of the same length (in quarters), we break ties by using the highest earning spell. Instrumental variables for jobs obtained (any, direct-hire and temporaryhelp) are contractor by year of assignment dummies. All models include dummy variables for year by quarter of assignment and assignment-district by year of assignment, and controls for sex, white or Hispanic race, other race, age and agesquared, total quarters employed and total earnings in eight quarters prior to Work First assignment, total quarters employed in temporary help agency work and total temporary help agency earnings in eight quarters prior to Work First assignment. Earnings values inflated to 2003 dollars using the Consumer Price Index (CPI-U). $\sim p \leq 0.10,{ }^{*} p \leq 0.05$, ** $\mathrm{p} \leq 0.01$. 
Table 6

Two-Stage Least Squares Estimates of the Effect of Work First Job Placements on Earnings and Employment by Sector over 8 Quarters: Direct-Hire and

Temporary Help Jobs

\begin{tabular}{|c|c|c|c|c|c|c|}
\hline & \multicolumn{2}{|c|}{ All Jobs } & \multicolumn{2}{|c|}{ Direct-Hire Jobs } & \multicolumn{2}{|c|}{ Temp-Help Jobs } \\
\hline & $\begin{array}{c}\text { Q 1-4 } \\
\text { (1) }\end{array}$ & $\begin{array}{c}\text { Q 5-8 } \\
(2) \\
\end{array}$ & $\begin{array}{c}\text { Q 1-4 } \\
\text { (3) }\end{array}$ & $\begin{array}{c}\text { Q 5-8 } \\
(4) \\
\end{array}$ & $\begin{array}{c}\text { Q 1-4 } \\
\text { (5) }\end{array}$ & $\begin{array}{c}\text { Q 5-8 } \\
(6)\end{array}$ \\
\hline & \multicolumn{6}{|c|}{ A. Earnings } \\
\hline Direct Hire Job & $\begin{array}{l}2,453^{*} \\
(598)\end{array}$ & $\begin{array}{l}1,720 \text { * } \\
(621)\end{array}$ & $\begin{array}{l}2,121 \text { * } \\
(457)\end{array}$ & $\begin{array}{l}1,711 * \\
(625)\end{array}$ & $\begin{array}{r}362 \\
(290)\end{array}$ & $\begin{array}{r}-28 \\
(145)\end{array}$ \\
\hline Temp Agency Job & $\begin{array}{r}-308 \\
(545)\end{array}$ & $\begin{array}{r}-882 \\
(583)\end{array}$ & $\begin{array}{c}-1,470 \text { * } \\
(417)\end{array}$ & $\begin{array}{r}-593 \\
(652)\end{array}$ & $\begin{array}{l}1,042 \text { * } \\
(318)\end{array}$ & $\begin{array}{r}-226 \\
(182)\end{array}$ \\
\hline Constant & $\begin{array}{l}3,233 \\
(222)\end{array}$ & $\begin{array}{l}4,254 \\
(227)\end{array}$ & $\begin{array}{l}2,875 \\
(158)\end{array}$ & $\begin{array}{l}3,693 \\
(224)\end{array}$ & $\begin{array}{r}313 \\
(123)\end{array}$ & $\begin{array}{l}509 \\
(62)\end{array}$ \\
\hline $\mathrm{R}^{2}$ & 0.24 & 0.20 & 0.21 & 0.18 & 0.08 & 0.03 \\
\hline $\mathrm{H}_{0}:$ Temp=Direct & 0.00 & 0.01 & 0.00 & 0.03 & 0.03 & 0.33 \\
\hline & \multicolumn{6}{|c|}{ B. Quarters Employed } \\
\hline Direct Hire Job & $\begin{array}{c}0.94 \text { * } \\
(0.19)\end{array}$ & $\begin{array}{c}0.45^{*} \\
(0.17)\end{array}$ & $\begin{array}{l}0.97 \text { * } \\
(0.13)\end{array}$ & $\begin{array}{c}0.40^{*} \\
(0.16)\end{array}$ & $\begin{array}{r}-0.02 \\
(0.11)\end{array}$ & $\begin{array}{r}-0.03 \\
(0.05)\end{array}$ \\
\hline Temp Agency Job & $\begin{array}{r}0.13 \\
(0.13)\end{array}$ & $\begin{array}{r}-0.21 \\
(0.15)\end{array}$ & $\begin{array}{l}-0.38 \text { * } \\
(0.11)\end{array}$ & $\begin{array}{r}0.01 \\
(0.18)\end{array}$ & $\begin{array}{c}0.49 * \\
(0.10)\end{array}$ & $\begin{array}{r}-0.09 \\
(0.06)\end{array}$ \\
\hline Constant & $\begin{array}{r}1.58 \\
(0.07)\end{array}$ & $\begin{array}{r}1.70 \\
(0.06)\end{array}$ & $\begin{array}{r}1.25 \\
(0.04)\end{array}$ & $\begin{array}{r}1.41 \\
(0.05)\end{array}$ & $\begin{array}{r}0.31 \\
(0.04)\end{array}$ & $\begin{array}{r}0.28 \\
(0.02)\end{array}$ \\
\hline $\mathrm{R}^{2}$ & 0.20 & 0.14 & 0.19 & 0.12 & 0.12 & 0.09 \\
\hline $\mathrm{H}_{0}:$ Temp=Direct & 0.00 & 0.02 & 0.00 & 0.18 & 0.00 & 0.03 \\
\hline
\end{tabular}

$\mathrm{N}=37,163$. Robust standard errors in parentheses are clustered on Work First contractor (33 clusters). Each column corresponds to a separate 2SLS regression. Instrumental variables for jobs obtained (any, direct-hire and temporary-help) are contractor by year of assignment dummies. All models include dummy variables for year by quarter of assignment and assignment-district by year of assignment, and controls for sex, white or Hispanic race, other race, age and age-squared, total quarters employed and total earnings in eight quarters prior to Work First assignment, total quarters employed in temporary help agency work and total temporary help agency earnings in eight quarters prior to Work First assignment. Earnings values inflated to 2003 dollars using the Consumer Price Index (CPI-U).

$\sim p \leq 0.10,{ }^{*} p \leq 0.05,{ }^{* *} p \leq 0.01$. 
Table 7

Comparison of Alternative Instrumenal Variables and Estimators for the Effect of Job Placements on Employment and Earnings in 8 Quarters Following Work

First Assignment

\begin{tabular}{|c|c|c|c|c|c|c|}
\hline & \multicolumn{2}{|c|}{$\begin{array}{l}\text { IVs: Contractor } \times \\
\text { Year Dummies }\end{array}$} & \multicolumn{2}{|c|}{$\begin{array}{l}\text { IVs: Contractor } \\
\text { Dummies }\end{array}$} & \multicolumn{2}{|c|}{$\begin{array}{l}\text { IVs: Placement } \\
\text { Rates Excluding } \\
\text { Own Cohort }\end{array}$} \\
\hline & 2SLS & LIML & 2SLS & LIML & 2SLS & LIML \\
\hline & $(1)$ & $(2)$ & $(3)$ & $(4)$ & $(5)$ & $(6)$ \\
\hline & \multicolumn{6}{|c|}{ A. Earnings } \\
\hline Direct Hire Job & $\begin{array}{r}4,173 \text { * } \\
(1,175)\end{array}$ & $\begin{array}{r}4,336 \text { * } \\
(1,053)\end{array}$ & $\begin{array}{r}4,923 \text { * } \\
(1,987)\end{array}$ & $\begin{array}{l}5,123 \text { * } \\
(1,370)\end{array}$ & $\begin{array}{l}4,671 \text { * } \\
(1,717)\end{array}$ & $\begin{array}{r}4,671 \\
(1,444)\end{array}$ \\
\hline Temp Agency & $\begin{array}{r}-1,190 \\
(999)\end{array}$ & $\begin{array}{r}-1,738 \\
(1,580)\end{array}$ & $\begin{array}{r}-2,120 \\
(1,299)\end{array}$ & $\begin{array}{r}-2,510 \\
(1,842)\end{array}$ & $\begin{array}{r}-2,168 \\
(1,386)\end{array}$ & $\begin{array}{r}-2,168 \\
(2,048)\end{array}$ \\
\hline Constant & $\begin{array}{l}7,487 \\
(426)\end{array}$ & $\begin{array}{l}7,477 \\
(384)\end{array}$ & $\begin{array}{l}7,294 \\
(681)\end{array}$ & $\begin{array}{l}7,255 \\
(489)\end{array}$ & $\begin{array}{l}7,392 \\
(588)\end{array}$ & $\begin{array}{l}7,392 \\
(481)\end{array}$ \\
\hline $\mathrm{R}^{2}$ & 0.25 & 0.25 & 0.25 & 0.24 & 0.25 & 0.25 \\
\hline \multirow[t]{2}{*}{$\mathrm{H}_{0}:$ Temp=Direct } & 0.00 & 0.00 & 0.02 & 0.00 & 0.01 & 0.02 \\
\hline & \multicolumn{6}{|c|}{ B. Quarters Employed } \\
\hline Direct Hire & $\begin{array}{l}1.38 \text { * } \\
(0.34)\end{array}$ & $\begin{array}{l}1.46 \text { * } \\
(0.25)\end{array}$ & $\begin{array}{l}1.46 \text { * } \\
(0.62)\end{array}$ & $\begin{array}{l}1.56 \text { * } \\
(0.33)\end{array}$ & $\begin{array}{r}1.56 \text { * } \\
(0.51)\end{array}$ & $\begin{array}{r}1.55 \text { * } \\
(0.34)\end{array}$ \\
\hline Temp Agency & $\begin{array}{l}-0.09 \\
(0.23)\end{array}$ & $\begin{array}{r}-0.29 \\
(0.37)\end{array}$ & $\begin{array}{r}-0.43 \\
(0.33)\end{array}$ & $\begin{array}{r}-0.62 \\
(0.44)\end{array}$ & $\begin{array}{r}-0.38 \\
(0.34)\end{array}$ & $\begin{array}{l}-0.38 \\
(0.48)\end{array}$ \\
\hline Constant & $\begin{array}{r}3.27 \\
(0.12)\end{array}$ & $\begin{array}{r}3.26 \\
(0.09)\end{array}$ & $\begin{array}{r}3.28 \\
(0.21)\end{array}$ & $\begin{array}{r}3.26 \\
(0.12)\end{array}$ & $\begin{array}{r}3.24 \\
(0.17)\end{array}$ & $\begin{array}{r}3.24 \\
(0.11)\end{array}$ \\
\hline $\mathrm{R}^{2}$ & 0.21 & 0.20 & 0.19 & 0.18 & 0.19 & 0.19 \\
\hline $\mathrm{H}_{0}:$ Temp=Direct & 0.00 & 0.00 & 0.03 & 0.00 & 0.02 & 0.01 \\
\hline
\end{tabular}

$\mathrm{N}=37,163$. Robust standard errors in parentheses are clustered on Work First contractor (33 clusters). Odd-numbered columns contains two-stage least squares estimates. Even-numbered columns contained limited information maximum liklihood estimates. Instruments are: columns 1 and 2, assigned contractor by year; columns 3 and 4, assigned contractor; columns 5 and 6 , fraction of individuals placed in temporary help and direct hire jobs at the contractor to which the participant was assigned in the same year, excluding all participants assigned in the same week.

All models include dummy variables for year by quarter of assignment and assignment-district by year of assignment, and controls for sex, white or Hispanic race, other race, age and age-squared, total quarters employed and total earnings in eight quarters prior to Work First assignment, total quarters employed in temporary help agency work and total temporary help agency earnings in eight quarters prior to Work First assignment. Earnings values inflated to 2003 dollars using the Consumer Price Index (CPI-U). $\sim p \leq 0.10,{ }^{*} p$ $\leq 0.05,{ }^{* *} \mathrm{p} \leq 0.01$. 
Table 8

Models for the Average and Marginal Characteristics of Participants Obtaining Temporary Help and Direct-Hire Jobs during their Work First Spells

\begin{tabular}{|c|c|c|c|c|}
\hline & \multicolumn{2}{|c|}{$\begin{array}{c}\text { Prior } 8 \text { Quarters of } \\
\text { Earnings }\end{array}$} & \multicolumn{2}{|c|}{$\begin{array}{c}\text { Prior } 8 \text { Quarters of } \\
\text { Employment }\end{array}$} \\
\hline & OLS & $2 S L S$ & OLS & $2 S L S$ \\
\hline & $(1)$ & $(2)$ & $(3)$ & $(4)$ \\
\hline & \multicolumn{4}{|c|}{ A. All Employers } \\
\hline Direct Hire & $\begin{array}{c}10,256 \\
(288)\end{array}$ & 10,049 & 4.47 & 4.35 \\
\hline Temp Agency & $\begin{array}{l}10,447 \\
(403)\end{array}$ & $\begin{array}{l}8,699 \\
(910)\end{array}$ & $\begin{array}{l}4.52 \\
(0.07)\end{array}$ & $\begin{array}{l}4.13 \\
(0.21)\end{array}$ \\
\hline $\mathrm{R}^{2}$ & 0.28 & 0.27 & 0.60 & 0.60 \\
\hline $\mathrm{H}_{0}: \mathrm{B}_{\mathrm{OLS}}=\mathrm{B}_{2 S L S}$ & & 0.27 & & 0.15 \\
\hline \multirow[t]{2}{*}{$\mathrm{H}_{0}:$ Direct-Hire $=$ Temp } & 0.54 & 0.25 & 0.42 & 0.35 \\
\hline & \multicolumn{4}{|c|}{ B. Temporary-Help Employers } \\
\hline Direct Hire & $\begin{array}{c}1,071 \\
(30)\end{array}$ & $\begin{array}{c}641 \\
(161)\end{array}$ & $\begin{array}{c}0.72 \\
(0.02)\end{array}$ & $\begin{array}{l}0.60 \\
(0.06)\end{array}$ \\
\hline Temp Agency & $\begin{array}{c}1,840 \\
(84)\end{array}$ & $\begin{array}{c}971 \\
(213)\end{array}$ & $\begin{array}{l}1.13 \\
(0.03)\end{array}$ & $\begin{array}{l}0.67 \\
(0.11)\end{array}$ \\
\hline $\mathrm{R}^{2}$ & 0.07 & 0.06 & 0.18 & 0.16 \\
\hline $\mathrm{H}_{0}: \mathrm{B}_{\mathrm{OLS}}=\mathrm{B}_{2 S L S}$ & & 0.00 & & 0.00 \\
\hline $\mathrm{H}_{0}:$ Direct-Hire=Temp & 0.00 & 0.29 & 0.00 & 0.62 \\
\hline \multicolumn{5}{|c|}{$\begin{array}{l}\mathrm{N}=37,163 \text {. Robust standard errors in parentheses are clustered on } \\
\text { Work First contractor ( } 33 \text { clusters). Each column corresponds to a } \\
\text { separate OLS or } 2 \text { SLS regression. Instrumental variables for jobs } \\
\text { obtained (any, direct-hire and temporary-help) are contractor by year of } \\
\text { assignment dummies. All models include dummy variables for year by } \\
\text { quarter of assignment and assignment-district by year of assignment. } \\
\text { Earnings values are inflated to } 2003 \text { dollars using the Consumer Price } \\
\text { Index (CPI-U). } \sim p \leq 0.10,{ }^{*} p \leq 0.05,{ }^{* \star} p \leq 0.01 \text {. }\end{array}$} \\
\hline
\end{tabular}


Appendix Table 1

P-Values of Tests of Random Assignment of Participant Demographic Characteristics across Work First Contractors with Randomization Districts, 1999 - 2003

\begin{tabular}{|c|c|c|c|c|c|c|c|c|c|c|c|c|c|}
\hline & \multicolumn{13}{|c|}{ Randomization District } \\
\hline & 1 & II & III & IV & $\mathrm{V}$ & $\mathrm{VI}$ & VII & VIII & IX & $\mathrm{x}$ & $\mathrm{XI}$ & XII & All \\
\hline \multicolumn{14}{|c|}{$1999-2000$} \\
\hline P-value & 0.51 & 0.10 & 0.65 & 0.20 & $\mathrm{n} / \mathrm{a}$ & 0.12 & 0.80 & $\mathrm{n} / \mathrm{a}$ & 0.79 & 0.89 & 0.86 & 0.66 & 0.62 \\
\hline $\mathrm{N}$ & 1,864 & 720 & 708 & 1,412 & & 954 & 807 & & 697 & 794 & 690 & 676 & 9,322 \\
\hline \multicolumn{14}{|c|}{$2000-2001$} \\
\hline P-value & 0.36 & 0.16 & 0.01 & 0.31 & & 0.55 & 0.98 & & 0.66 & 0.85 & 0.92 & 0.25 & 0.35 \\
\hline $\mathrm{N}$ & 1,462 & 1,381 & 498 & 1,384 & $\mathrm{n} / \mathrm{a}$ & 954 & 682 & $\mathrm{n} / \mathrm{a}$ & 145 & 849 & 527 & 1,484 & 9,366 \\
\hline \multicolumn{14}{|c|}{$2001-2002$} \\
\hline P-value & 0.13 & 0.10 & 0.07 & 0.33 & 0.34 & 0.44 & 0.73 & 0.35 & $\mathrm{n} / \mathrm{a}$ & 0.99 & 0.63 & 0.49 & 0.18 \\
\hline $\mathrm{N}$ & 2,006 & 1,589 & 1,042 & 1,423 & 923 & 957 & 932 & 1,102 & & 784 & 372 & 1,614 & 12,744 \\
\hline \multicolumn{14}{|c|}{$2002-2003$} \\
\hline P-value & 0.38 & 0.95 & 0.34 & 0.95 & 0.81 & 0.58 & 0.65 & 0.18 & $\mathrm{n} / \mathrm{a}$ & 0.76 & $\mathrm{n} / \mathrm{a}$ & 0.08 & 0.76 \\
\hline $\mathrm{N}$ & 717 & 634 & 332 & 715 & 642 & 436 & 476 & 382 & & 419 & & 978 & 5,731 \\
\hline \multicolumn{14}{|l|}{ All Years } \\
\hline $\mathrm{P}$-value & 0.21 & 0.14 & 0.02 & 0.46 & 0.64 & 0.41 & 0.98 & 0.21 & 0.84 & 1.00 & 0.96 & 0.18 & 0.44 \\
\hline $\mathrm{N}$ & 6,049 & 4,324 & 2,580 & 4,934 & 1,565 & 3,301 & 2,897 & 1,484 & 842 & 2,846 & 1,589 & 4,752 & 37,163 \\
\hline
\end{tabular}

Each cell provides the $p$-value from a Seemingly Unrelated Regression for the null hypothesis that the 10 main sample covariates are balanced across clients assigned to Work First contractors within the relevant assignment district and year cell. Covariates tested are sex, white or Hispanic race, other race, age and age-squared, total quarters employed and total earnings in eight quarters prior to Work First assignment, total quarters employed in temporary help agency work and total temporary help agency earnings in eight quarters prior to Work First assignment. Right-hand column and bottom row provide analogous test statistics pooling across districts either within a year or across years within a district. Bottom right-hand cell provides the test statistic for all districts and years simultaneously. Cells marked "n/a" indicate that there was only one contractor operating in the district during most or all of the indicated year. 
Appendix Table 2

The Effect of Work-First Job Placements on Wage and Salary Earnings in Eight Quarters Following Work First Assignment: Sample Limited to First Work-First Spell for Each Participant

\begin{tabular}{|c|c|c|c|c|}
\hline & \multicolumn{2}{|c|}{ A. Earnings } & \multicolumn{2}{|c|}{ B. Quarters } \\
\hline & OLS & 2SLS & OLS & 2SLS \\
\hline & $(1)$ & $(2)$ & $(3)$ & $(4)$ \\
\hline Direct Hire Job & $\begin{array}{l}4,705 \\
(176)\end{array}$ & $\begin{array}{c}\text { * } 5,388 \text { * } \\
(1,258)\end{array}$ & $\begin{array}{c}1.32 \\
(0.05)\end{array}$ & * $\begin{array}{c}1.59 \\
(0.38)\end{array}$ \\
\hline Temp Agency Job & $\begin{array}{l}3,759 \\
(272)\end{array}$ & $\begin{array}{c}*-2,334 \text { * } \\
(977)\end{array}$ & $\begin{array}{c}1.23 \\
(0.07)\end{array}$ * & $\begin{array}{l}-0.66 \\
(0.25)\end{array}$ \\
\hline Constant & $\begin{array}{c}7,693 \\
(84)\end{array}$ & $\begin{array}{l}7,995 \\
(486)\end{array}$ & $\begin{array}{c}3.32 \\
(0.03)\end{array}$ & $\begin{array}{c}3.39 \\
(0.13)\end{array}$ \\
\hline $\mathrm{R}^{2}$ & 0.26 & 0.24 & 0.23 & 0.19 \\
\hline $\mathrm{H}_{0}:$ Temp=Direct & 0.00 & 0.00 & 0.13 & 0.00 \\
\hline \multicolumn{5}{|c|}{$\begin{array}{l}\mathrm{N}=24,903 \text {. Robust standard errors in parentheses are clustered } \\
\text { on Work First contractor ( } 33 \text { clusters). Each column } \\
\text { corresponds to a separate OLS or } 2 \text { SLS regression. } \\
\text { Instrumental variables for jobs obtained (any, direct-hire and } \\
\text { temporary-help) are contractor by year of assignment dummies. } \\
\text { All models include dummy variables for year by quarter of } \\
\text { assignment and assignment-district by year of assignment, and } \\
\text { controls for sex, white or Hispanic race, other race, age and age- } \\
\text { squared, total quarters employed and total earnings in eight } \\
\text { quarters prior to Work First assignment, total quarters employed } \\
\text { in temporary help agency work and total temporary help agency } \\
\text { earnings in eight quarters prior to Work First assignment. } \\
\text { Earnings values inflated to } 2003 \text { dollars using the Consumer } \\
\text { Price Index (CPI-U). } \sim p \leq 0.10,{ }^{*} p \leq 0.05, * * p \leq 0.01 \text {. }\end{array}$} \\
\hline
\end{tabular}


Appendix Table 3

Comparing Instrumental Variables Estimates of the Efffect of Direct Hire and Temporary Help Placements on Earnings and Employment over Eight Quarters while Including Endogenous Variables Individually and Simultaneously

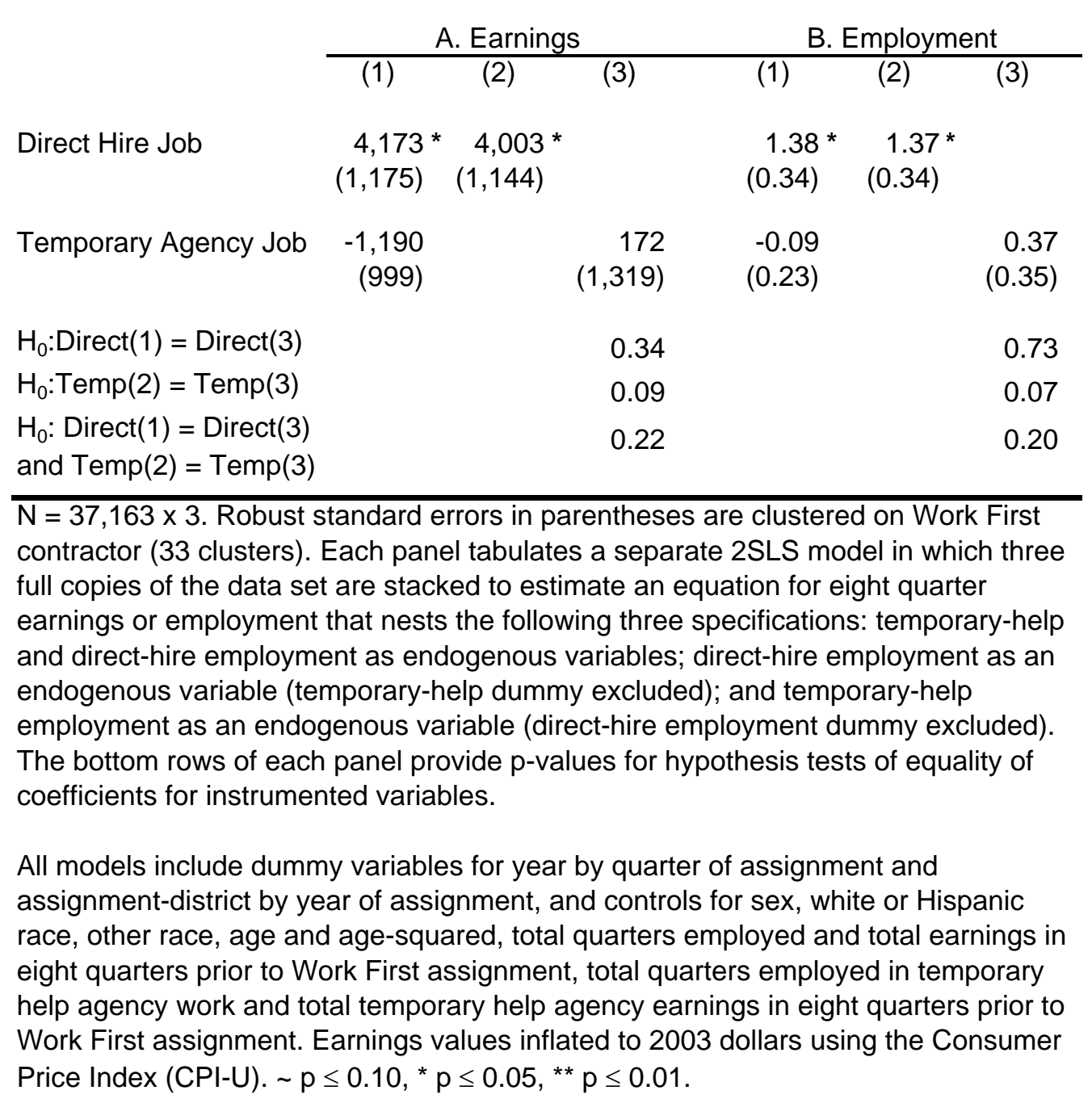

